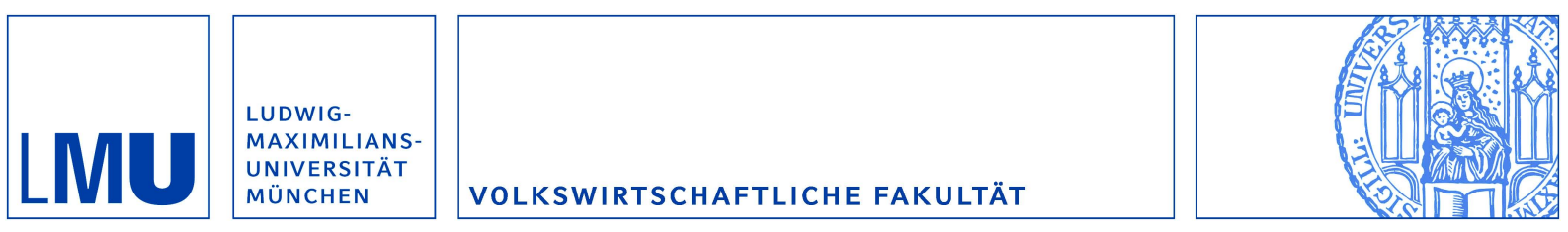

Urbschat, Florian:

The Good, the Bad, and the Ugly: Impact of Negative Interest Rates and QE on the Profitability and Risk-Taking of 1600 German Banks

Munich Discussion Paper No. 2018-7

Department of Economics

University of Munich

Volkswirtschaftliche Fakultät

Ludwig-Maximilians-Universität München

Online at https://doi.org/10.5282/ubm/epub.56535 


\title{
The Good, the Bad, and the Ugly: \\ Impact of Negative Interest Rates and QE on the Profitability and Risk-Taking of 1600 German Banks
}

\author{
Florian URBSCHAT \\ UNIVERSITY OF MUNICH \\ Seminar for Macroeconomics \\ Ludwigstr. 28, Room 019a \\ 80333 Munich, Germany
}

Click here for the latest version of the paper.

This version: July 9, 2018

\begin{abstract}
The recent negative interest rate policy (NIRP) and quantitative easing (QE) programme by the ECB have raised concerns about the pass-through of monetary policy. On the one hand, negative rates could lead to declining bank profitability making an expansionary monetary policy contractionary. Also, if interest rates are too low for too long banks could be induced to take too much risky credit. On the other hand, several economists argue that there is nothing special about negative interest rates per se. This paper uses a large micro level data set of the German bank universe to examine how banks behave in this uncharted territory. The evidence found suggests that bank's business model, i.e. the share of overnight deposits, plays a crucial role. While some banks may benefit in the short run via for instance reduced refinancing costs or lower loan loss provisions, many banks with high deposit ratios face lower net interest income and lower credit growth rates. If continued for too long QE and NIRP erode bank profits for most banks eventually.
\end{abstract}

JEL Codes: C53, E43, E52, G11, G21

Keywords: Negative Interest Rate Policy, Banks' Profitability, Net Interest Rate Margin, Risk-Taking Channel

\begin{abstract}
Acknowledgements: This paper was supported by the Research Data and Service Centre of the German Bundesbank, which provided the data. I am thankful to several Bundesbank employees, most notably Harald Stahl, who provided technical assistance related to data issues. Moreover, I am thankful to Piergiorgio Alessandri, Christoph Basten, Stefan Bender, Peter Bofinger, Markus Brunnermeier, Lukas Buchheim, Jens Eisenschmidt, Stephan Fahr, Ulrich Fritische, Hesna Genay, Florian Heider, Joao Granja, Christian Hirsch, Gerhard Illing, Mike Mariathasan, Ricardo Reis, Farzad Saidi, Haresh Sapra, Isabel Schnabel, Mathias Trabandt, Michael Weber, Volker Wieland, Jing Cynthia Wu, and Peter Zorn for valuable advice. I also appreciated helpful comments and suggestions from presentations at the MGSE Ph.D. Colloquium 2017, the Macroeconomics Seminar at the University of Munich, the ifo Macro Seminar, the Bundesbank, the 11th RGS Doctoral Conference in Economics, the Chicago Booth Finance Brownbag, the German Council of Economic Experts, the University of Hamburg, the ECB, and the CESifo 2018 Area conference in Macro, Money, and International Finance. Any errors are the responsibility of the author Florian Urbschat.
\end{abstract}

Monthly balance sheet statistics DOI: 10.12757/BBk.BISTA.99Q1-16Q4.01.01

Banks' profit and loss statements DOI:10.12757/Bbk.GuV.9316.01 


\section{Introduction}

In order to fight deflationary tendencies in the Euro Area, the ECB announced several rounds of unconventional monetary policy (UMP) measures since 2014. Most notable in this respect were the introduction of a negative interest rate policy (NIRP) on bank deposits in June 2014 and the announcement of a quantitative easing (QE) programme in January 2015. While most of the on-going discussion has been focused on the impact on inflation, real GDP growth, or the financial markets, the focus of this paper is on potential side effects of QE and NIRP with respect to bank income, risk-taking, and the pass-through of monetary policy. From a financial stability perspective lowering both the level and the slope of the yield curve is potentially worrisome for two main reasons. First, it could erode bank profits over time reducing their skin-in-the-game and, second, it could lead to more risk-taking by banks.

To shed light on these concerns, this paper uses a large micro level data set of 1600 German banks. The large number of banks allows exploiting heterogeneity as banks in the data set vary in size, degree of internationality, and their business models. This is important for several reasons: First, many of the smaller savings or cooperative banks are a crucial lender to small and medium sized enterprises in Germany and other European countries. Second, these banks rely more on deposits as a funding source and might be more severely hit by NIRP than large global players using various sources of funding. Most importantly, the share of deposits is crucial for the pass-through at negative rates as argued by e.g. Eggertsson et al. (2017) and Drechsler et al. (2017). However, most of the existing literature has a much smaller sample of mainly large international banks compared to the one used in this paper ${ }^{1}$.

To estimate the effect of NIRP and QE on bank income and loan growth rates this paper proposes three different approaches. The baseline regression uses a Fixed Effect (FE) and Dynamic System Generalised Methods of Moments (System-GMM) estimator with an interaction term between the level of the short-term interest rate and the bank specific ratio of overnight deposits as a source of funding. To assess if going negative is a game changer for banks with a high deposit ratio, a simple dummy is introduced from 2014 onwards. Admittedly, this is a crude measure as these years could be special for many other reasons such as new capital regulations. Therefore, as a second and more innovative approach, I use the implied shadow rate estimated by Wu and Xia (2017) to better account for the strength of UMP. The idea here is to capture both negative rates and the reduction in the slope of the yield curve via QE. Third, as an additional robustness check, I use a difference-in-difference (diff-in-diff) estimator where banks with a high deposit ratio are defined as the treatment group and low deposit banks serves as the control group.

In general, one can think of several channels how monetary policy can influence bank lending and income during normal and unconventional times. The standard monetary transmission channel may influence bank lending in the following way. After a cut in short-term interest rates, banks should

\footnotetext{
${ }^{1}$ In addition, German banks are particularly interesting due to the fact that Germany has been subject to vast capital inflows in the recent years via the Target II payment system. Following the announcement of NIRP and QE policies, the Target II imbalances have widened again indicating that most of the excess liquidity enters into the German banking system. Therefore, holding above average excess liquidity relative to their European peers, German banks could be more severely hit by these UMP measures.
} 
pass on lower interest rates to their customers increasing the demand for loans by firms and households (interest rate channel). At the same time, as interest rates and asset prices are inversely correlated, asset prices rise making firms and households more wealthy (wealth channel). Subsequently, banks are also more willing to grant additional credit against the higher valued collateral (balance sheet channel). In addition, the rise in asset prices should also boost bank income as they benefit from capital gains on their profit and loss $(\mathrm{P} \& \mathrm{~L})$ statements $^{2}$. As a result, bank equity increases relaxing their equity constraint which facilitates further loan issuance (equity constraint channel). Moreover, with lower interest rates the domestic currency should depreciate which leads to an increase in foreign demand (exchange rate channel). Finally, following the positive economic outlook existing credit lines are likely to have a lower probability of default as firms and households find it easier to roll-over debt (credit channel). Taken together, all the described channels should increase real economic growth and, ultimately, increase inflation. Also, all these developments should boost bank profits and, hence, foster financial stability. However, some authors, such as Borio and Zhu (2012), argue that if rates are too low for too long bank lending could become excessive (risk-taking channel) leading to bubbles in the real sector which in contrast may endanger financial stability.

Although these channels are reasonably well understood in normal times, it is not clear how they behave below the zero lower bound (ZLB). On the one hand, authors such as Brunnermeier and Koby (2017) and Rognlie (2016) argue that there is nothing special about moderate negative interest rates per se. This view is also shared by, for instance, the Swedish and Swiss central banks claiming that the interest rate pass-through continues even with slightly negative rates ${ }^{3}$. The income of financial intermediaries is not determined by the level of the interest rate but rather by the spread between the borrowing and the lending rate, the so called net interest rate margin (NIM). Thus, we may be worried about the flattening of the yield curve but not necessarily about NIRP.

On the other hand, Eggertsson et al. (2017) and Demiralp et al. (2017) find that the standard mechanisms of monetary policy cease to function at negative interest rates due to several frictions ${ }^{4}$. While central banks can lower their deposit facility into negative territory leading to higher costs for banks, it is more difficult for banks to pass these additional costs on to their clients and introduce negative interest rates on their deposits. Put differently, whereas the short-term asset side of banks' balance sheets can follow into negative territory, the short-term liability side is floored at zero leading to a under representation of the true refinancing cost for banks ${ }^{5}$. In particular, this is a concern for

\footnotetext{
${ }^{2}$ Yet, in practice not all banks benefit equally from capital gains due to different business models and the accounting standards at hand. For example, smaller banks often hold assets to maturity and are thus less likely to benefit from capital gains compared to larger investment banks having a sizeable trading portfolio which is mark-to-market.

${ }^{3}$ See Riksbank (2015) and Jordan (2016).

${ }^{4}$ These frictions can come in various forms. While the existence of currency as cash is the most important one, offering a zero yield outside alternative store of value, some authors also mention institutional constraints such as tax restrictions, legal concerns about negative interest rates for households, or IT barriers in dealing with negative rates. However Bech and Malkhozov (2016) find that most of these technical constraints have been resolved shortly after the introduction of negative rates.

${ }^{5}$ As a rule of thumb the storage costs of cash is lower for smaller amounts. In this context, Scheiber et al. (2016) find that some banks have already introduced negative interest rates for larger firms, which typically need great amounts of liquidity, but not for households.
} 


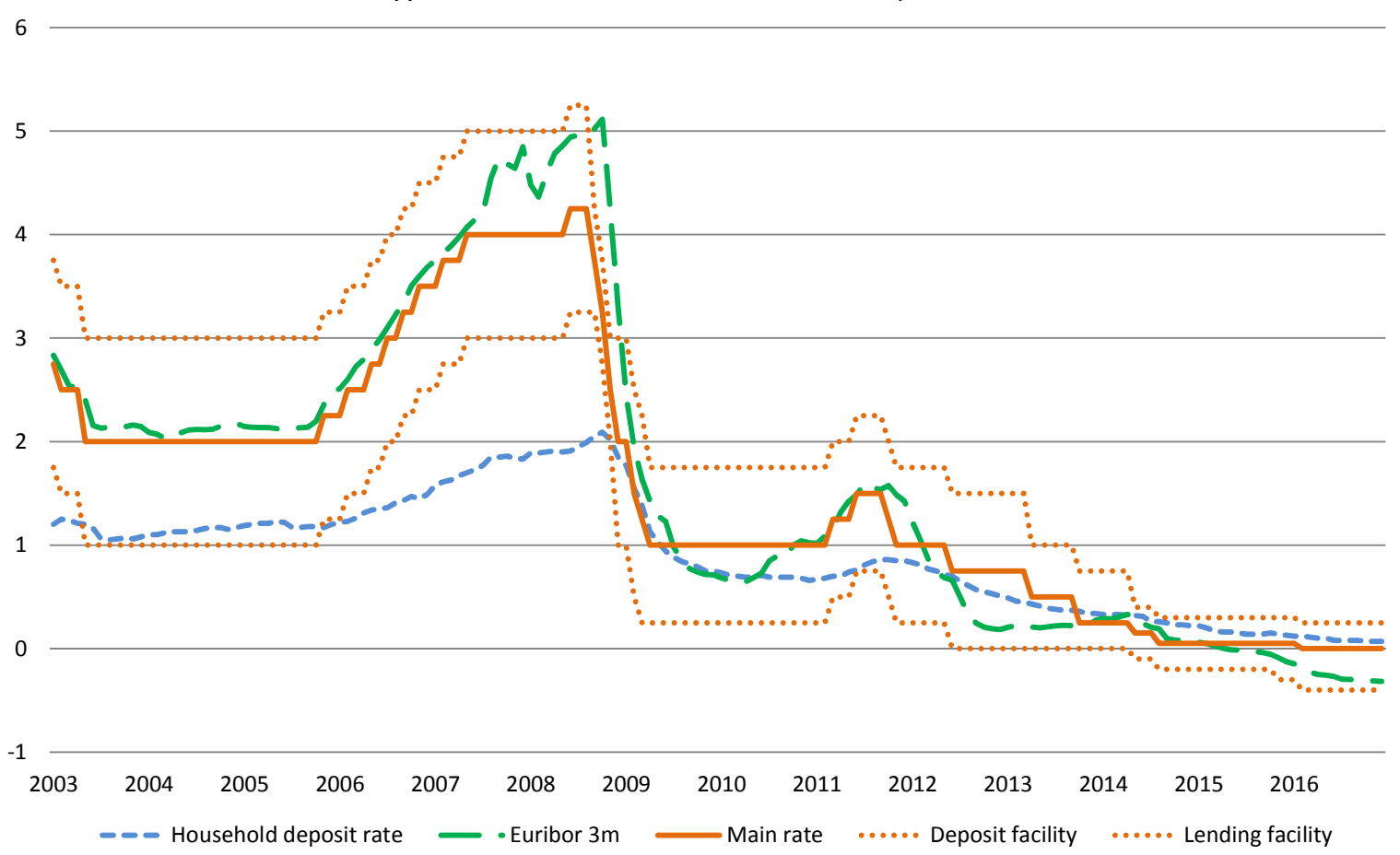

Source: ECB Statistical Data Warehouse, MIR data set. Aggregate overnight household deposit rate for Germany.

retail banks with large deposit holdings as a source of financing. In contrast, larger investment banks with greater market power might find it easier to raise other sources of short-term funding, e.g. from wholesale funding or the corporate bond market. Aggregate data from Germany presented in Figure 1 suggests that deposit rates on households are in fact constrained by the ZLB whereas interbank lending rates can follow in to negative territory.

Still, the wider impact of negative interest rates is a mostly uncharted territory with several economists making conflicting predictions. Therefore, the general structure of this empirical paper is to take the common pro and contra arguments in the literature seriously and to study their empirical relevance.

The spread between short- and long-term interest rates has a systematic effect on bank profits. It is well understood that banks' intrinsic business model is to borrow short and to lend long. Hence, a positive-sloped yield curve leads to a positive NIM via the classic maturity transformation. It is usually the case that lowering short-term interest rates helps to boost bank profits, since the spread between short-term liabilities and long-term assets widens. Figure 2 illustrates the change in the yield curve after a reduction in short-term policy rates in a stylised way. Suppose, as in panel A, a bank with a long-term asset legacy holds only fixed interest paying assets. As these assets continue to pay the old higher interest rates, a decline in the short end of the yield curve increases the profits of this bank due to reduced refinancing costs and a higher margin. In contrast, if the same bank would hold only floating interest paying assets and liabilities, as in panel B, profits are practically unaffected assuming assets and liabilities have the same size, as found by Busch and Memmel (2015). Since the long end of yield curve 
Figure 2: Lowering a Hypothetical Yield Curve: Impact on Net Interest Margins
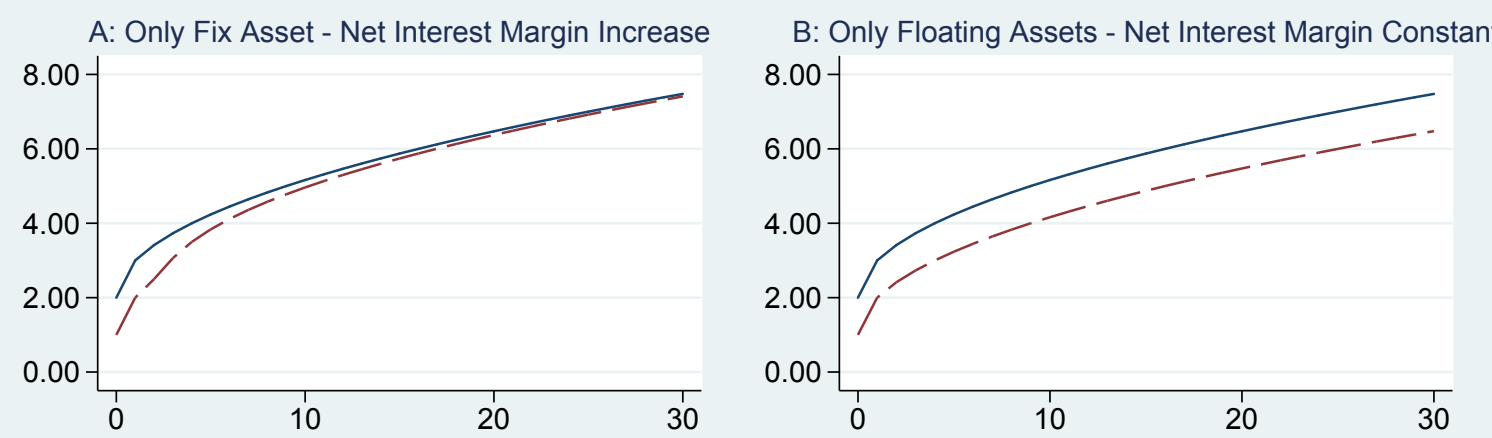

C: At the ZLB - Net Interest Margin Decrease
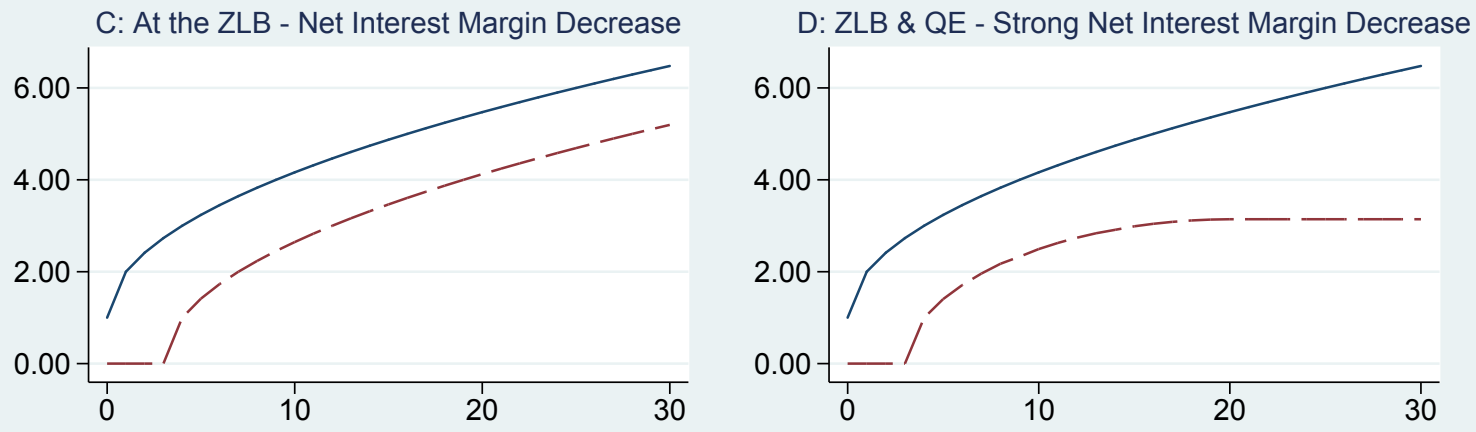

\section{Initial yield curve $\quad--$ Response to monetary policy}

Source: Own illustration. X-axis shows maturity, Y-axis shows yield. Numbers are chosen simply for illustrative purposes. Hypothetical old yield curve in blue. Response of yield curve to monetary policy in red.

typically follows the short-term rate over time, a reduction in short-term rates leads to a simple parallel shift of the yield curve. Also note that in the long run, all fixed assets are replaced or rolled over by new assets paying the current market interest rate. Hence, panel A usually applies to the short run whereas panel B captures the long run effects all else equal.

However, as for instance argued by Kerbl and Sigmund (2017), breaking through the zero lower bound is a game changer since short-term assets can follow into negative regions while overnight deposits cannot. If banks are charged with a negative interest rate when depositing excess liquidity at the central bank, many of these banks are unable to directly pass these additional costs on to their clients. Subsequently, their NIM narrows as panel C illustrates. In such a situation, banks could either try to change their liability structure (e.g. by switching from deposits financing to wholesale financing), increase interbank lending ${ }^{6}$, or charge additional fees (indirectly passing negative rates on to costumers). To which extent these strategies help to mitigate adverse effects of NIRP on interest margins is largely unknown. In

\footnotetext{
${ }^{6}$ However, banks cannot be able to change the aggregate excess liquidity in the system. In fact, some banks might successfully reduce their short-term funding overhang via interbank lending. Yet, this strategy cannot be feasible for the system as a whole. Someone inevitably ends up holding the excess liquidity which is best illustrated by the "hot potato effect".
} 
addition to NIRP, the QE programme of the ECB is explicitly targeted at long-term maturities flattening the slope of the yield curve. These two measures taken together could reduce the net interest margin of banks considerably as shown in panel D. Therefore, bank profits might be strongly impaired by low NIMs potentially inducing banks to greater risk-taking.

According to the notion of the risk-taking channel ${ }^{7}$ an increase in the quantity of credit could be accompanied by a simultaneous decline in the quality of credit. More precisely, several sources of risktaking can be identified. Traditional portfolio allocation models predict a negative relationship between risk-taking and monetary policy. Since a lower interest rate on safe assets gives incentives to investors to reallocate their portfolio towards securities with higher yields, the overall riskiness of the portfolio rises. At the same time, a lower risk-free rate also lowers the hurdle rate for some investment projects which may have a high risk profile. As an increasing number of risky projects are financed by banks the overall quality of the investment pool worsens. In addition, banks could engage in more extensive maturity transformation or raise their leverage due to limited liabilities considerations. The temptation for a hazardous behaviour could be stronger if banks find it hard to generate enough profits via reasonably safe credits. Heider et al. (2017) stress that this behaviour is likely during negative interest rate periods due to a decline in banks' net worth. This undermines their incentives for prudent behaviour and careful screening of borrowers. Moreover, Demertzis and Wolff (2016) point out that when banks earn a smaller margin on credits, they may try to increase volume of credits to counteract the drop in margins. This provides an additional incentive for banks to excessively expand their supply of loans.

However, the good news from the evidence presented in this paper is that banks overall do not engage in high risk-taking by granting an excessive amount of credit or by reducing their lending standards. Moreover, following the recent changes in the Basel requirements the majority of banks have improved their leverage ratio over the last years. Regarding their income situation, NIRP does not pose a large cost burden on banks; instead they benefit from the current low refinancing rates and face lower loan loss provisions due to the positive macro-economic environment and low interest burden for borrowers. On the other hand, the bad news is that banks neither benefit from increased fee income (as fees are not proportional to deposits) nor from capital gains following high asset prices, which is among others due to the conservative German accounting law. In addition, banks face increasing excess liquidity on the asset side and increasing overnight deposits on the liability side of their balance sheets highlighting the fact that the aggregate liquidity overhang in the system does not vanish. Taking this fact together with the extended interest rate fixation period by banks creates a potential source of risk as the maturity mismatch rises. Moreover, higher deposit ratios are problematic as especially these banks on average have a lower net interest income calling into question the pass-through of monetary policy. While it is true that average credit growth rate has increased, this macro-view misses a reshuffling of credit growth from banks with high- to banks with low deposit ratios, which is only revealed by micro level bank data. Therefore, this paper argues that the ugly truth is that NIRP and QE are starting to get contractionary

\footnotetext{
${ }^{7}$ See Borio and Zhu (2012), Adrian and Shin (2010), or Dell'Ariccia et al. (2014).
} 
for banks with high deposit ratios as they have already reduced their lending growth rates. Also, as many benefits are short-lived it remains unclear how long the positive aspects of QE and NIRP can prevail before they are outweighed by the long-term negative impact on banks and the monetary pass-through. In other words, for the same reason that banks now can benefit from lower refinancing rates, in a few a years when interest rates rise again this might pose great challenges for banks with a large share of low yield and high maturity assets.

The remainder of this paper is structured as follows. Section 2 gives an overview on the literature of bank profitability and risk-taking. Afterwards, Section 3 provides details about the German banking system and the data set at hand. A descriptive analysis from this data set is presented in Section 4 followed by a more in depth regression analysis in Section 5 and a simple robustness check in Section 6 . Finally, Section 7 concludes.

\section{Literature Review}

This paper is related to three broadly defined strands of the literature: Bank risk-talking, bank profitability, and the impact of conventional and unconventional monetary policy (mostly NIRP and QE) on both. In contrast to much of the existing literature examining large international banks, this paper focuses on exploiting the heterogeneity among different bank business models within a single major European economy. Also, focusing on just one country makes banks largely independent from varying business cycles in different countries, which is a usual concern with international bank data.

First of all, important contributions on how low interest rates affect bank risk-taking via the risktaking channel have been made by Borio and Zhu (2012), Adrian and Shin (2010), and Dell'Ariccia et al. (2014). In addition to these theoretical work, many studies examine empirically how bank risk-taking is affected if conventional monetary policy keeps interest rates too low for too long, including Ioannidou et al. (2015), Maddaloni and Peydró (2011), Jiménez et al. (2014), and Dell'ariccia et al. (2017). Despite many studies find a negative relationship between the level of short-term interest rates and bank risktaking, there is no clear consensus whether less capitalised banks are more or less prone to risk-taking. For example, Dell'ariccia et al. (2017) find that risk-taking is more pronounced for well capitalised banks due to risk shifting. On the other hand, Jiménez et al. (2014) argue that least capitalised banks react stronger to changes in monetary policy by taking more risk when monetary policy is eased. They find that in times of low interest rates, banks with less capital are those which are more prone to agency problems and, thus, grant more credit to ex ante risky firms.

The second important strand of the literature relates to bank income or bank profitability. Several authors have made important contributions to the topic of bank profitability both theoretically and empirically, see for instance English (2002) on bank interest rate risk and the NIM, English et al. (2014) showing that in the short run the capital gains channel outweighs changes in the net interest margin, Alessandri and Nelson (2015) indicating that large banks try to reduce yield curve risk by hedging 
against changes in income margins through interest rate derivatives, Bolt et al. (2012) on the impact of the business cycle on bank income, and Busch and Memmel (2015) who examine how the level of interest rates affects banks' net interest margin. In a related paper, Busch and Memmel (2016) decompose the different components of this margin.

While all these papers focus on normal times, this paper relates to several recent contributions on the impact of unconventional monetary policy on bank profitability and risk-taking ${ }^{8}$. Interesting theoretical models on the exact level of the lower bound come from Rognlie (2016) and Brunnermeier and Koby (2017) on the reversal interest rate. At some tipping point, lowering the short-term interest rate reduces banks' NIM and squeezes their profits. Since banks are equity constrained, a decline in profits might force banks to reduce their loan business which makes an expansionary monetary policy contractionary. Note that the level of the reversal interest rate does not necessarily have to be zero but rather can be higher or lower depending on various factors such as banks' balance sheet structure, their dividend policies, or the general economic environment.

So far, most of the empirical studies examine the impact of low or negative interest rates on a more aggregate level, such as Jobst and Lin (2016) or on large international banks as in Altavilla et al. (2014). Using the same data set on international banks, Borio, Gambacorta, and Hofmann (2017) focuses on the impact of low interest rates on bank profitability while Borio and Gambacorta (2017) is a similar study but focuses more on bank lending and risk-taking. Also, there exists a growing literature on the country specific experience with NIRP, see for instance Scheiber et al. (2016) for a study on Denmark and Sweden, Basten and Mariathasan (2018) for Switzerland, Kerbl and Sigmund (2017) for the Austrian banking sector, and Ahtik et al. (2016) for Slovenia. In addition to the effects of negative interest rates, other authors focus on the effects of large scale asset purchase programmes such as Lambert and Ueda (2014) and Demertzis and Wolff (2016) arguing that a QE policy boosts bank profits in short run, but the flattening of the yield curve may lead to a decline of bank income over the long-term.

Similar to this paper is the work of Borio, Gambacorta, and Hofmann (2017) who examined for a time period from 1995 to 2012 how certain profitability measures of banks (e.g. net interest income or other non-interest income) are explained by a monetary policy indicator and the slope of the yield curve. Their findings indicate that important non-linearities are present if interest rates are close to the ZLB. More precisely, the impact of monetary policy on bank income is particularly large when interest rates are unusually low and the yield curve is flat, leading to an erosion of bank profitability over time.

A second related paper from Demiralp et al. (2017) puts emphasis on bank balance sheet adjustments following the introduction of negative interest rates. Focusing on large Euro Area banks the authors distinguish between banks holding excess liquidity and those who do not. They find that treated banks tend to give more loans, purchase more non-domestic government bonds, and lower their levels of wholesale funding.

\footnotetext{
${ }^{8}$ This third strand of the literature is growing fast, especially since the introduction of NIRP by the Danish Nationalbank (July 2012), the European Central Bank (June 2014), the Swiss National Bank (January 2015), the Swedish Riksbank (February 2015), and by the Bank of Japan (February 2016).
} 
Another recent paper by Heider et al. (2017) focuses on bank risk-taking behaviour after the introduction of a NIRP. The authors argue that banks with large deposits are not able to pass negative interests on to their customers. Using a difference-in-difference approach their paper shows that banks with a higher share of deposit funding lend less and to riskier borrowers. This additional risk-taking would increase the moral hazard problem of managing loans and ultimately raise financial stability issues.

More generally, there is a lively discussion to which degree monetary policy decisions should take financial stability considerations into account which is, among others, largely influenced by the work of Svensson (2015) and Stein (2014).

\section{The German Banking System and the Data Set}

Before describing the data set in detail, this section discusses some specialities of the German banking sector in general. More importantly, the differences between the internationally known IFRS accounting standards and the German GAAP (Handelsgesetzbuch - HGB) are described. While economist often abstract from such technical details, a basic understanding of the rather conservative German accounting standards is key to the right interpretation of the results as the HGB largely influences the underlying data generating process ${ }^{9}$.

Several important aspects distinguish the German banking system from an Anglo-Saxon banking system. First of all, Germany has a universal banking system which is divided into the so-called three pillar system of private banks, cooperative banks, and public (savings) banks. Typically, private banks are found mostly in larger cities, have more wealthy private customers, and are more active in lending to larger firms, whereas cooperative and savings banks are dominant in the rural areas and in lending to private households and small companies. Moreover, all three pillars can be further split into subcategories. Most noteworthy are the four largest private banks (the so-called "Major banks") having branches all across the country. These are also the banks which are most active on the global markets. In contrast, the so-called "regional banks" are smaller private banks often focusing on some regional or topical niche market such as car financing. The second pillar of cooperative banks is mainly characterised by a special legal form and the cooperative principle. The largest subgroup in this pillar are the so-called "Volksbanken und Raiffeisenbanken". Finally, the distinguishing feature of the third pillar is that public banks are fully or partially owned by a public entity, which can be federal, regional, or county based. While most banks in this pillar are public saving banks, usually owned by a city or a municipality, the

\footnotetext{
${ }^{9}$ One might argue that looking at banks' balance sheets and P\&L statement to identify banks profitability is potentially misleading from an economic perspective. In fact, following a rise in asset prices, the solvency of any bank improves from an economic viewpoint irrespective whether a bank can capitalise these gains or not. However, this pure economic view could miss two important factors which are relevant in the real world. First of all, from an investors viewpoint it could make a difference if capital gains enter into profits or not. On the one hand, the investor receives a potentially larger dividend and, on the other hand, if banks seem financially more solid on their balance sheet, investors are more likely to provide fresh funding when banks face unexpected financial difficulties. Second, and more importantly, accounting standards can have a direct impact on banks' regulatory equity and therefore on the borrowing constraints banks face. For example, capital gains from asset holdings in the trading portfolio enter directly into the P\&L statement. Hence, the available bank equity increases next period, and this bank is able to lend more to the real sector. See also Beatty and Liao (2014) for a recent survey on the effect of accounting standards at banks.
} 
so-called "Landesbanken" (state banks) are owned by the German states.

A second important feature of the German banking system is the house bank principle which is widely spread, in particular among smaller banks ${ }^{10}$. Under the house bank principle, banks are also interested in the long-term success of their customers and might for instance be more willing to provide liquidity when needed. However, a house bank system has several merits and drawbacks. On the one hand, long standing credit relationships usually decrease information asymmetries between lender and borrower. This can overcome typical micro inefficiencies such as moral hazard or adverse selection problems, leading to lower screening costs for banks and, thus, can reduce credit rationing. Furthermore, long lasting credit relationships often make it easier for small and medium sized enterprises to raise cash when needed. On the other hand, the house bank principle also provides banks with some monopoly power which may result in inefficient lending conditions for firms and households. With respect to negative interest rates, this could in principle enable banks to more easily raise fees and commissions, effectively passing negative interest rates on to their clients.

Finally, as pointed out by Dombret et al. (2017), several studies have shown that the German banking system is, compared to its international peers, on average not as profitable. For instance, data by the OECD indicates that the average cost-to-income structure is significantly higher for many German institutions than for other international banks. As Dombret et al. (2017) argue, these high values result from lower revenue generation rather than higher costs. Moreover, German banks seem to have the highest dependency on interest rate income compared to banks in other OECD countries. A potential reason for this under average performance of German banks could be the relatively high share of savings and cooperative banks in the German banking sector. In contrast to the monopoly argument made above, Dombret et al. (2017) argue that both kinds of banks rely heavily on deposit financing and, thus, might find it harder to pass additional costs associated with excess liquidity onto their customers. Also, as these smaller banks typically hold fewer assets being mark-to-market, their revenues could drop even further potentially making them strongly impaired by UMP measures in the Euro Area.

In general, fair value accounting is not as common under the German HGB as it is under the internationally relevant IFRS rules. In contrast, the principle of prudence is very dominant in German accounting. The basic idea of this principle is that a firm or bank should not gloss over its financial situation to provide protection to creditors. On the other hand, this often implies that the balance sheet representation is worse than the actual economic position. Two important concepts which materialise the principle of prudence are the so called realisation principle and the imparity principle. Under the realisation principle revenues can only be considered in the profit and loss statement if the cash flow has actually realised, which is in strong contrast to IFRS or US GAAP standards where revenues only have to be realisable. Moreover, this is complemented by the imparity principle treating profits and losses differently. On the liability side all foreseeable and realisable risks and losses have to be taken into account. This is put in more concrete terms by the so called lowest value principle for assets and

\footnotetext{
${ }^{10}$ See for instance Harhoff and Körting (1998) for an early study.
} 
highest value principle for liabilities. For example, the lowest value principle requires that assets must be impaired if the fair value is less than their carrying amount ${ }^{11}$. For long-term assets impairments can be revised if the reasons for the initial write down do not exist anymore.

However, since the implementation of the "Bilanzrechtsmodernisierungsgesetz" (Balance Sheet Modernisation Act) in 2010 fair value representation has been partially introduced in the German accounting standards. While the Balance Sheet Modernisation Act changed the accounting rules for several balance sheet positions such as defined benefit obligations, goodwill, or taxes, the most important two changes for this paper concern the treatment of financial derivatives and the introduction of a trading book which is held at fair value ${ }^{12}$. In fact, a mark-to-market trading book partially undermines both the realisation principle and the imparity principle as gains can now enter into the profit and loss statement without having actually realised.

While all these changes are very important for the German "Major banks" and the Landesbanken due to their more international business model and their larger trading portfolios, they are of second relevance for savings and cooperative banks. Capitalising financial derivatives in late 2010 effects both the size and the composition of the balance sheet of these international banks (see Figure 12 for total assets, Figure 14 for the asset composition, and Figure 15 for liabilities in the Appendix). In contrast, smaller banks have typically have a more conservative business models, do not engage in hedging activities, and often hold a very small trading book. Therefore, it is reasonable to assume that the positive effects of unconventional monetary policy measures via capital gains do not benefit smaller banks to a great extent. To get a better understanding of the relevant income components, Table 1 presents the income statements of German banks in a stylised form. Position A shows the net interest rates received which is simply the difference between all interest rates paid and all interest rates received. As a result of banks' role as financial intermediaries and their maturity transformation, this position is usually positive and the major source of income for all German banks. In contrast, the position B (net commissions received) can be either positive or negative since some banks rely heavily on brokers on the financial markets. This is similar for position D (net income or net charges from the valuation of assets) which can also be positive or negative. More precisely, it provides the net value adjustments with respect to loans and securities. Note that this position also captures the important provisions (or reversals of provisions) for loans. Other important cost components relate to staff costs and other administrative spending.

As the HGB is the relevant accounting principle in Germany, all data collected by the Bundesbank

\footnotetext{
${ }^{11}$ Due to this property of the HGB rules, ever-greening of loans is not as common among German banks as in other jurisdictions. If loans are impaired they cannot be rolled over indefinitely to gloss banks' balance sheets but must be impaired instead.

${ }^{12}$ Under IFRS financial assets can be classified as either held-for-trading, held-for-sale, or held-to-maturity. While held-tomaturity assets are not mark-to-market, held-for-trading assets do enter the P\&L statement directly via fair value changes. On the other hand, gains and losses from available-for-sale financial assets do not enter the P\&L statement directly; instead they are a component of other comprehensive income. In contrast, under the new German HGB regulations assets can be categorised as either held-to-maturity or held-for-trading. The gains or losses from remeasurement of held-for-trading assets enter the P\&L statement directly via the net trading income. Value changes in held-to-maturity assets are accounted for in the net income from the valuation of assets and provisions. These changes are according to the highest and lowest value principle. The categorisation has to be made upon purchase and may not be changed at a later point in time, which is again in contrast to the IFRS rules providing more flexibility with respect to reclassification.
} 
Table 1: Profit and Loss Statement

\begin{tabular}{l|c|l} 
(A) & + & Net interests received \\
(B) & $+/-$ & Net commissions received \\
(C) & $+/-$ & Net profit or net loss from the trading portfolio \\
(D) & $+/-$ & Net income or net charges from the valuation of assets and provisions \\
(E) & - & Staff costs \\
(F) & - & Other administrative spending \\
(G) & $+/-$ & Net other and extraordinary income or charges \\
\hline & $=$ & Profit before tax \\
(H) & - & Taxes \\
\hline & $=$ & Total profit/loss for the financial year
\end{tabular}

is under HGB regulations. The total data set used in this paper ranges from January 2003 to December 2016 and is constructed by merging two distinctive data sets: the monthly bank balance sheet statistics and the yearly profit and loss statements. Both of these data sets were provided by the Research Data and Service Centre of the Bundesbank. As all banks holding a banking licence in Germany are obliged to fill in these two statistics the response rate is close to $100 \%$ (only positions smaller than 1,000 EUR are not mandatory to report $)^{13}$. As each bank reports at the individual bank level, no holdings are included.

After controlling for mergers by creating pro forma institutions ${ }^{14}$, there are roughly 1600 banks left in the data set. More precisely, these banks can be subdivided into 20 building societies, 981 cooperative banks, 1 cooperative central bank, 10 Landesbanken, 4 Major banks, 156 regional banks, 12 private mortgage banks, 403 savings banks, and 19 special purpose banks such as the KfW (a state owned German development bank). For the regression analysis these banks will be regrouped and defined as follows: large banks (Major banks, Landesbanken, and cooperative central banks), small banks (savings banks and cooperative banks), regional banks, and all other banks ${ }^{15}$. To deal with outliers the relevant variables are winsorised at the 1st and 99th percentile by bank group and year.

Finally, the data set is merged with additional control variables which are taken from Datastream and the German Statistics Office. The macro control variables are the quarterly real GDP growth, and a monthly house price index. Moreover, the monetary and financial control variables are the 3 month interbank lending rate (EURIBOR), the log of the German stock index DAX, and the yield of a 10 year German government bond. As an indicator for the strength of UMP I use the ECB implied shadow rate as provided by $\mathrm{Wu}$ and Xia (2017). All financial variables are averaged over each year when working with yearly data. A full list of variables can be found in the Appendix in Table 2.

\footnotetext{
${ }^{13}$ Also, more than $95 \%$ of all banks report over the whole observation period.

${ }^{14} \mathrm{~A}$ concern with this approach could be that mergers are endogenous. However, apart from a spike in late 2016 there does not seem to be a clear correlation between mergers and bank income. Moreover, the vast majority of mergers are horizontal mergers among savings or cooperative banks. As this group is by far the largest in the data set, only a small fraction of institutions is actually affected. Under the unlikely assumption that all 111 mergers since 2014 are a direct result of UMP, about $7 \%\left(\approx \frac{111}{1600}\right)$ of the banks in the data set would be affected. Running the regressions without pro forma institutions has no impact on the main results. For more details see Figure 13 in the Appendix.

${ }^{15}$ While this categorisation may seem ad hoc it captures the factual banking structure reasonable well. While only the three largest "small banks" overlap with the smallest "large bank", the residual group of "other bank" is admittedly more diverse. However, the alternative of grouping banks by total assets would come at the disadvantage of receiving more inconsistent groups with respect to banks' business model. Also, while the group of "other banks" varies strongly by size, the combining factor for these banks is a different liability structure. As Section 4 shows, all these banks have typically only long-term liabilities and very few overnight deposits.
} 


\section{Descriptive Analysis}

It is not trivial to answer the question how banks have reacted to the unconventional policy measures by the ECB, which flooded the financial markets with liquidity and set the deposit rate below zero. Some authors, such as Jobst and Lin (2016), predicted that due to the downward stickiness of deposit rates below zero, banks were encouraged to substitute wholesale funding for deposits. Especially for larger banks, wholesale funding could provide a cheaper alternative relative to retail deposits via the issuance of unsecured or covered bonds. In addition, banks could also try to escape the liquidity overhang by pushing off some customers with large deposits. This way banks may try to lower the costs they pay to the central bank. In contrast, the evidence presented in Figure 3, showing the average borrowing from households and firms relative to total assets, suggests that short-term deposits have increased for almost all banks. This development started already during the financial crisis in 2009, then ceased around 2011, and resumed in 2012 when the deposit rate was set to zero. Striking is the increase for smaller cooperative and savings banks in overnight borrowing (i.e. money on current accounts) from households relative to longer maturities (such as savings accounts). However, the share of overnight deposits also increased for major banks, regional banks, and the Landesbanken in the recent years. In contrast, building societies, private mortgage banks, and special purpose banks usually borrow at longer maturities, i.e. they are not affected to the same extend.

Figure 3: Average Borrowing from Households and Firms

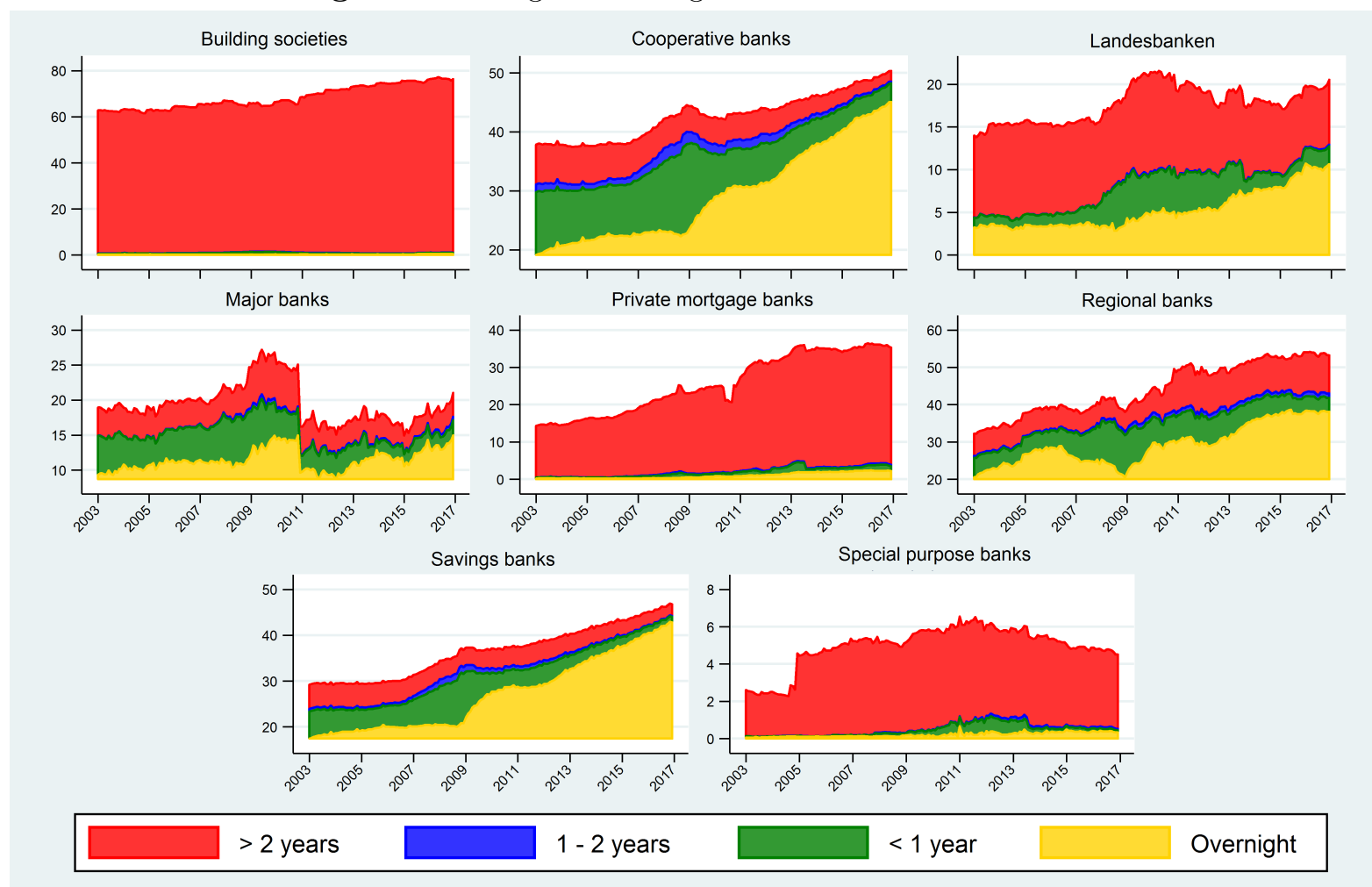

Source: Bundesbank Balance Sheet Statistics. Own calculations. Borrowing relative to total assets by bank group. The averages are calculated as weighted averages of total assets. 
However, this graph should be interpreted with caution. In fact, it does not tell anything about whether this development is driven by supply or demand effects. As this development started already before UMP measures, one can argue that it is simply driven by low opportunity costs of holding overnight deposits ${ }^{16}$ and liquidity preferences by households and firms. A recent paper by Drechsler et al. (2017) supports this argument. Also, one may argue that due to the vast amount of liquidity provided by the ECB since the financial crisis, banks on average are simply unable to escape the excess liquidity in the system and, hence, are forced to absorb additional short-term funding ${ }^{17}$. In this respect, it is crucial to understand that banks cannot simply "transform" short-term funding into credits to the real sector. In fact, if a bank grants a new credit to a firm or a household new deposits are created by the bank. Put differently, the creation of a new long-term asset (a real sector credit) goes hand in hand with the creation of a new short-term liability (in form of deposits).

Moreover, even if banks would decline to sell government bonds to the ECB, in order to keep longer term assets, the additional liquidity will ultimately end up on their balance sheet as a short-term asset and a short-term liability. To illustrate this point, suppose a bank declines to sell a government bond to the ECB under its QE programme. Instead, the ECB purchases the bond from a private agent, such as a hedge fund or an insurance company. This transaction leads to long-for-short asset exchange on the balance sheet of the private agent. Assuming that an ordinary private agent has a bank account, this transaction increases the short-term deposit on the private agent's bank account. On the flip side, from the bank's perspective the transaction implies an increase in short-term liabilities and short-term assets since the private agent now has larger deposit claims (a liability) and the transaction will initially be booked on the current account of the bank at central bank (an asset). Put differently, even if all banks would collectively decide not to sell a single bond to the ECB to avoid excess liquidity, they will end up holding the excess amount of short-term liquidity and would have to store it at the ECB. This explains the logic that the ECB "forces" banks to hold excess liquidity in large amounts. While these amounts are still rather minor relative to total assets, they are strongly increasing across all banks ${ }^{18}$. Major banks especially hold a small amount of excess liquidity in relative terms whereas regional banks hold the largest amount of excess liquidity on average as shown in Figure 4.

Therefore, the banking system as a whole is unable to escape the short-term liquidity overhang. As banks are unable to transform the short-term liquidity overhang into other long-term credits, this may lead to large extra costs for banks via the negative deposit rate. To evaluate this concern, this section first examines the development of the most important income and cost elements from the yearly profit and loss statements. In a second step, the current trends in some simple risk-taking measures are examined. I begin with the average bank income structure.

Arguably, one simple way for banks to counteract the costs related to negative interest rates charged

\footnotetext{
${ }^{16}$ In fact, some government bonds even have a negative yield providing even less incentive to invest.

${ }^{17}$ The recent widening of the TARGET imbalances suggests that much of this liquidity enters into the German financial system leaving German banks over-proportionally affected.

${ }^{18}$ Note that the data on excess liquidity holdings are not directly observable in the monthly balance sheet. In fact, the excess liquidity is calculated based on the daily in and outflow of payments on banks' current accounts at the central bank. Unfortunately, upon request the Bundesbank provided only aggregate data for some subsets of bank groups.
} 
Figure 4: Average Excess Liquidity by Bank Group
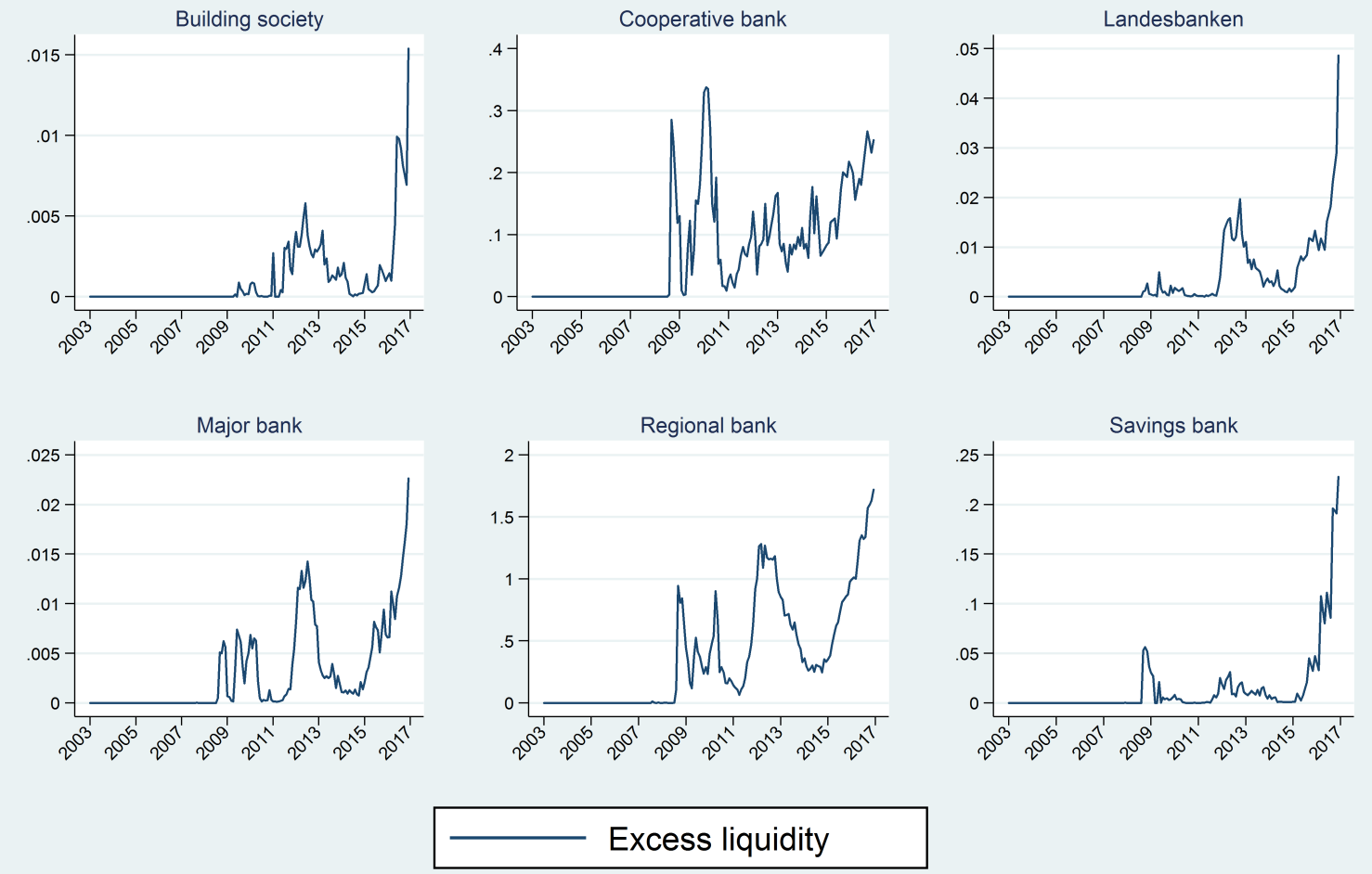

Source: Bundesbank. Own calculations. In percentage relative to total assets.

by the ECB would be to simply increase their commission and fees. However, as Figure 5 indicates this has not been the case to a large extend until the end of 2016. While the average total commission income is usually the second most important income component it is still relatively small and remarkably stable across all banking groups. Even though it is true that many banks have raised their account administration charges or their fees for transferring money recently, this additional income does not play a major role relative to total income as it is not proportional to the deposits. Unfortunately, the position commission income in the P\&L cannot be disentangled into it subcomponents of brokerage income or fees. In contrast, the income from interest rate payments is the most crucial income component of total income. The fluctuation in interest income largely determines the fluctuation of total income. On the other hand, income from the trading portfolio or the reversal of provisions are rather small for most bank groups, which is in contrast to the findings of Alessandri and Nelson (2015) who find larger trading income for UK banks. Even for the larger banks with sizeable trading portfolios the profits from trading are on average lower than $1 \%$ relative to total assets. One reason for the low income from trading is the conservative German Commercial Code (HGB). However, also under the more market based IFRS accounting principle the income from trading is clearly outweighed by the income from interest ${ }^{19}$.

The next natural question is how the different cost components have developed over time, which is shown in Figure 6. The widespread concern that negative interest rates pose a large cost burden for

\footnotetext{
${ }^{19}$ See Figure 16 in the Appendix for a simple comparison.
} 
Figure 5: Average Income Structure

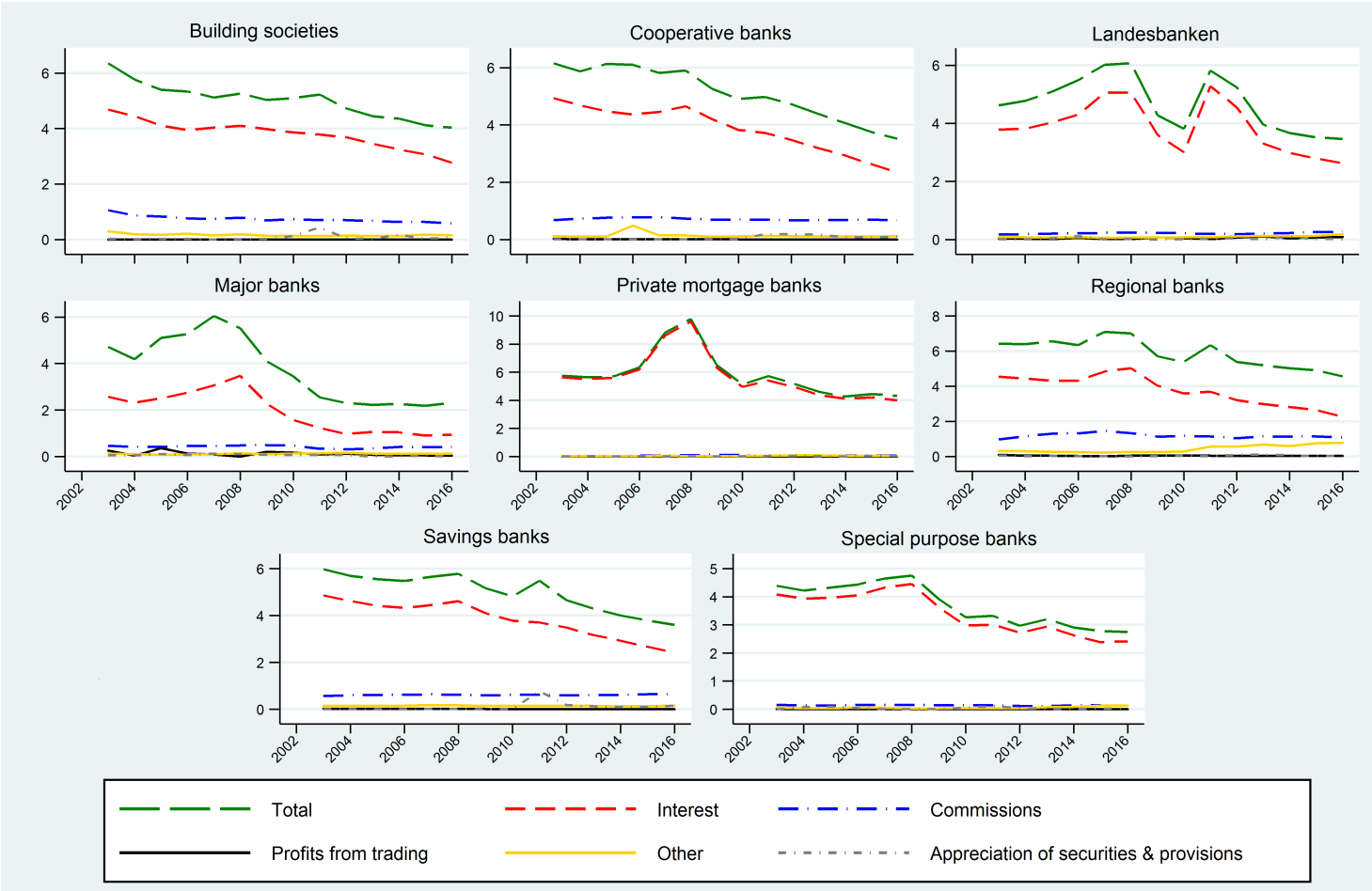

Source: Bundesbank P\&L Statistics. Own calculations. Income components as percentage relative to total assets by bank group. The averages are calculated as weighted averages of total assets.

banks due to increasing interest rate costs does not seem to hold. Rather, banks have largely benefited from declining interest rates, which is consistent with the classical view that banks borrow short and lend long. Since the financial crisis in 2008 interest costs are characterised by a clear downward trend across all banking groups. Again, interest rates are the most sizeable element of the total costs. Only in recent years staff costs have been larger than interest costs for cooperative and savings banks, which typically hold a large network of branches in rural areas. In addition, another positive effect arising from low interest rates is the decline in write downs and provisions. Due to low interest rates and the positive economic outlook in Germany, the relevance of write downs and provisions as a cost factor has mostly declined. In addition, commission costs are an important cost component for some banks such as building societies, which rely heavily on brokers. This holds also for regional banks where these costs increased slightly in recent years, potentially due to a higher search-for-yield and the related higher brokerage cost. With respect to the losses from the trading portfolio it is notable that only major banks suffered mentionable losses during the global financial crisis. Otherwise these costs do not play an important role.

Combing the various cost and income elements into the total net development of the P\&L statement shows that the net interest income, which is calculated by deducting the interest payments from the interest revenues, is remarkably constant over time. The net effect of income and cost components can be found in the Appendix in Figure 17 together with the evolution of the return on equity before and 
Figure 6: Average Cost Structure

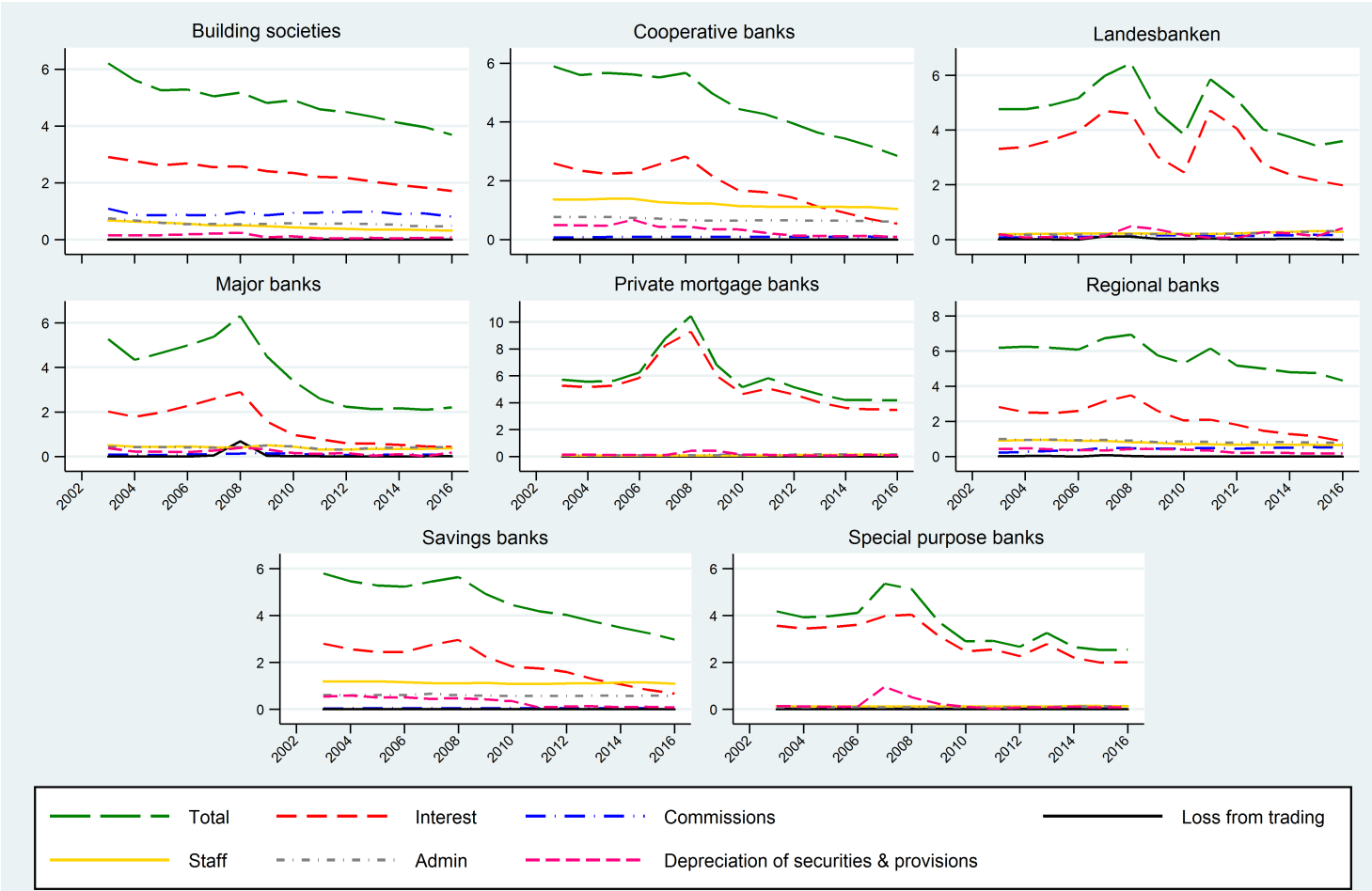

Source: Bundesbank P\&L Statistics. Own calculations. Cost components as percentage relative to total assets by bank group. The averages are calculated as weighted averages of total assets.

after taxes, which is shown in Figure 18.

With respect to bank risk-taking, Figure 7, 8, and 9 provide some primary evidence by illustrating the change over time in bank loan growth rates, the credit to GDP ratio, and the leverage ratio, respectively. In contrast, to what some have feared banks on average did not increase their risk-taking in these three dimensions after the introduction of NIRP or QE until the end of 2016.

Examining the growth rates of firm and household loans in more detail, Figure 7 illustrates that most bank groups have recently increased their loan rates. Interestingly, many German banks already extended their lending to firms and households during the financial crisis from 2008 till late 2009 and onwards. While the typical boom-and-bust credit cycles is found to be pro-cyclical to the GDP growth rates as illustrated in the case of the Landesbanken, many smaller German banks have extended their credit lines to their customers during the crisis. Most likely, this finding is, first, due to the house bank principle providing fresh funding in times of crisis and, second, due to firms and households making loan on overdrafts from their current account. However, given the visible volatility in loan growth rates, at which point can we think of loan growth rates and risk-taking as being excessive and when are they simply due to fundamentals of the economy? ${ }^{20}$

\footnotetext{
${ }^{20}$ As Cœuré (2016) argues, any risk-taking in terms of loan growth is "good" as long as it finances projects with a positive net present value. In contrast, risk-taking would only be "bad" if banks would finance projects with a negative net present value.
} 
Figure 7: Average Loan Growth to Households and Firms
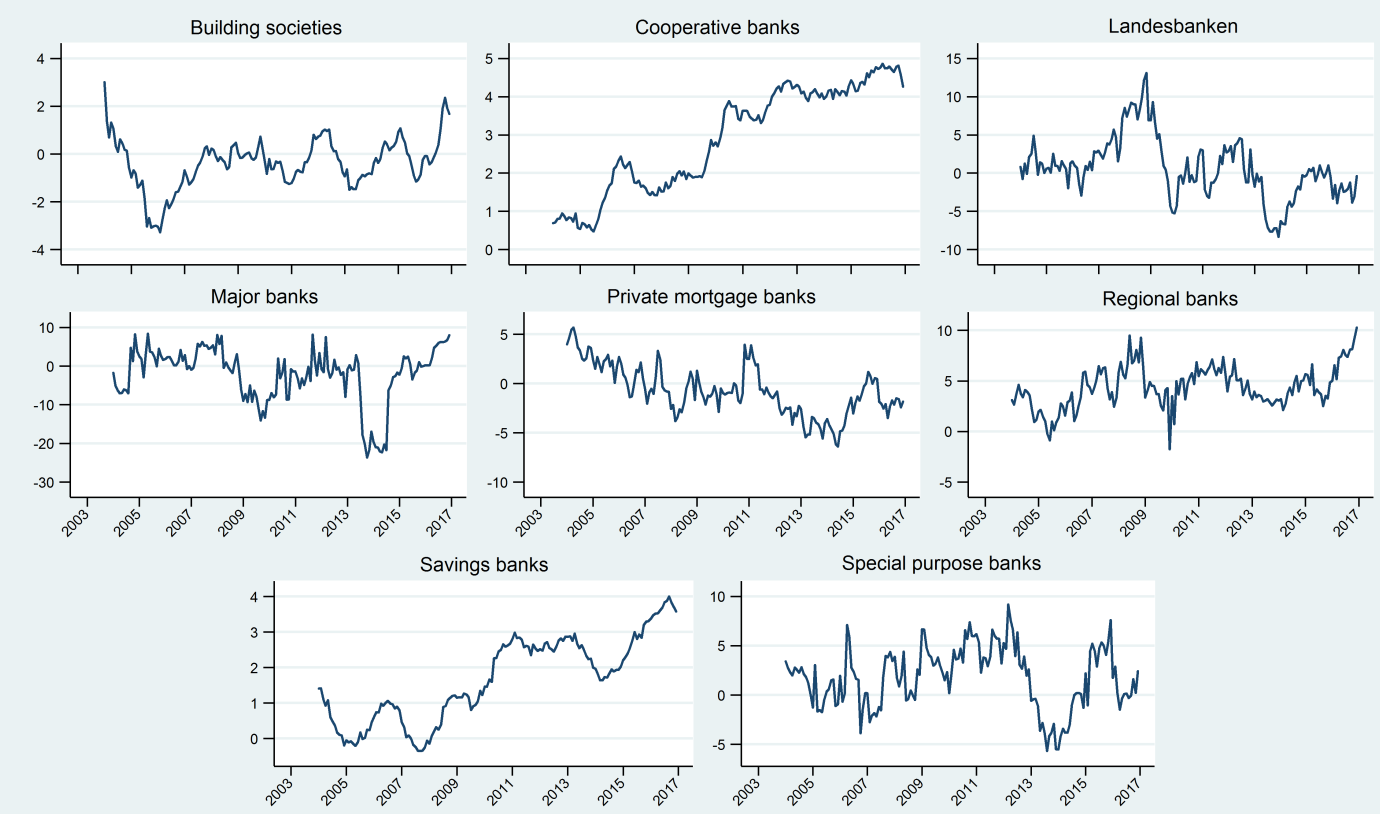

Special purpose banks

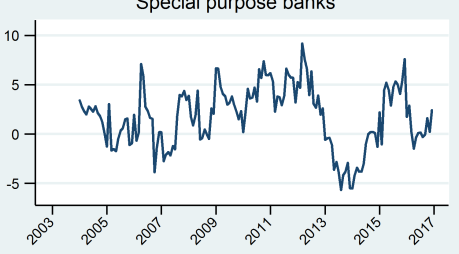

Non-bank loan, 1y growth

Source: Bundesbank Bank Balance Sheet Statistics. Own calculations. Growth calculated as year to year growth for each month. Averages are expressed as the median value of growth rates within each bank group.

Figure 8: Credit to GDP ratio

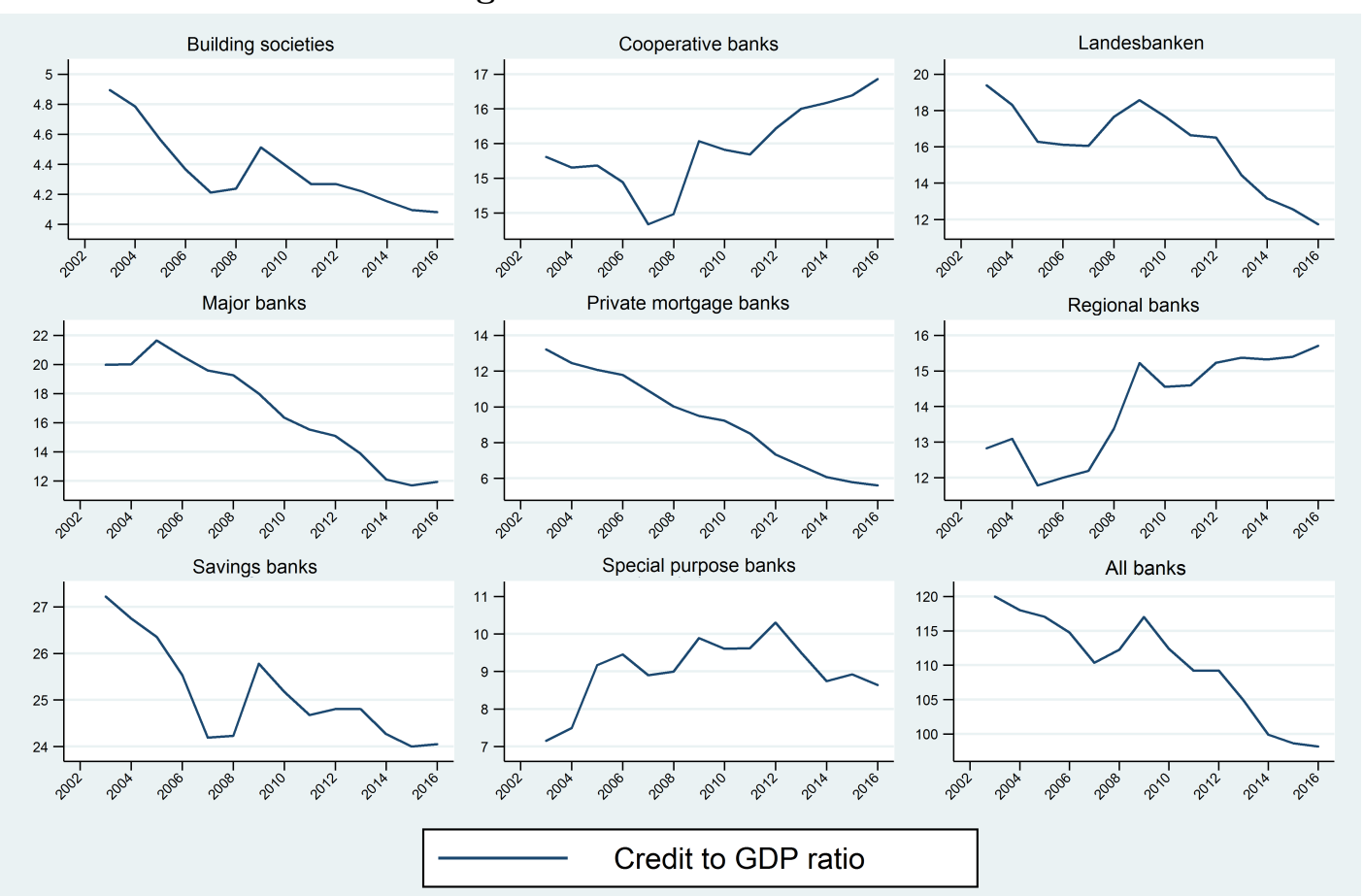

Source: Bundesbank Bank Balance Sheet Statistics. Own calculations. Growth calculated as year to year growth for each year. 
Figure 9: Average Leverage
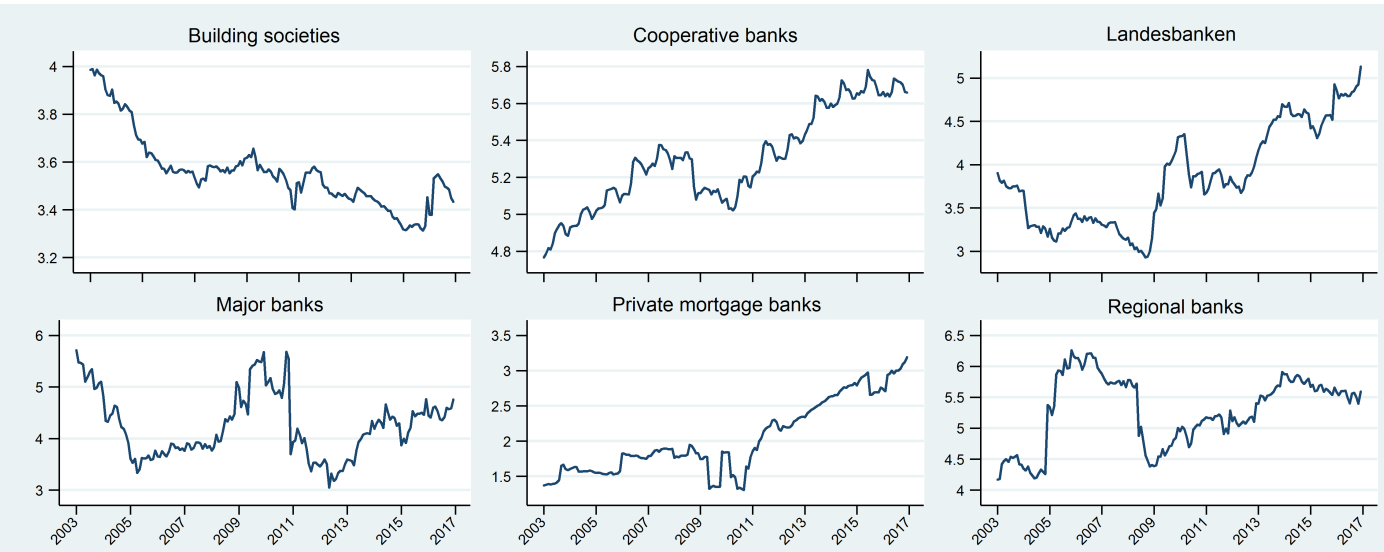

Savings banks

Special purpose banks

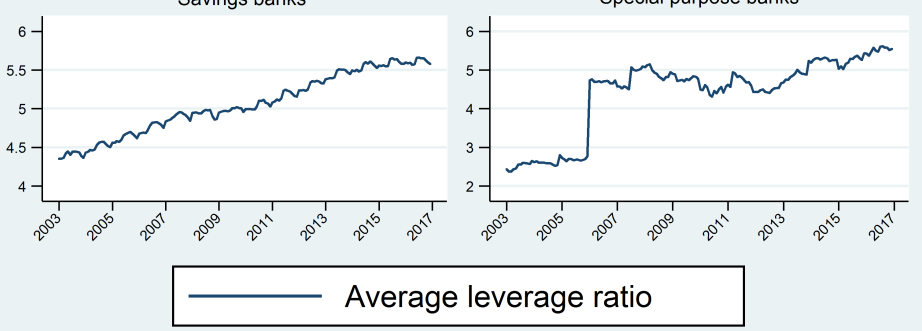

Source: Bundesbank Bank Balance Sheet Statistics. Own calculations. Leverage is defined as CET1 over total assets. The averages are calculated as weighted averages of total assets.

It is in general not easy to define which level of risk-taking can be considered as "excessive" or "normal". One guideline to this question is provided by the Basel III framework (The Basel Committee (2011)) which suggests considering the development of the credit to GDP ratio. Credit growth is considered to be excessive if the ratio deviates strongly upwards from its long-term trend. Figure 8 plots this ratio for all subgroups of German banks as well as the banking system as a whole. Only cooperative and regional banks exhibit a mild increase in the credit to GDP ratio in the recent years while the ratio is declining for all others banks as well as the total banking system. In other words, there is little indication that banks have taken an excessive amount of risk by issuing too much credit to risky firms or households since the start of NIRP and QE.

Another common measure to judge risk-taking is the leverage ratio, which is calculated by dividing a capital measure over a total exposure measure. Typically, this is done by taking core equity tier 1 (CET1) relative to total assets. In Germany, the core tier 1 capital largely consists of the paid-up capital and the reserves of an institution as defined in the Banking Act. Thus, the leverage ratio is calculated by the sum of subscribed capital and reserves divided by total assets ${ }^{21}$. As shown in Figure 9, most German banks have strengthened their leverage ratio over the last years. In this respect, the Basel III framework is already showing its bite even though the target rate of $3 \%$ is not yet fully phased-in.

\footnotetext{
${ }^{21}$ Note that this definition of the leverage ratio is only an approximation for the reported leverage ratio in banking supervision. Due to difference in accounting standards large international banks often get acknowledged other instruments as CET1. Put differently, the leverage ratio calculated here is a fair proxy for small German banks whereas it is a conservative estimate for large banks.
} 
Admittedly, examining banks' balance sheet statements to assess financial risk building up in the banking sector does not give a fully comprehensive picture. In fact, all measures presented until here are backward looking and can only help to answer the question if financial risk has already materialised in banks' balance sheets. However, they cannot serve as a forward looking predictor to detect future financial risk. To illustrate this point, one important caveat of Figure 7 is that it merely captures the quantity of loans but is ex ante silent on the quality of newly issued loans, which is only revealed at a future point in time. For example, if banks have lowered their lending standards and issued more risky credit, which would diminish the overall quality of their portfolio, they would be more vulnerable to negative shocks in the future. Therefore, in the remaining part of this section I present other aggregate statistics, which are not part of the data set I use, but can help to give a more comprehensive picture on bank risk-taking.

First of all, the empirical evidence provided by the bank lending survey ${ }^{22}$ shown in Figure 10 does not indicate that banks lowered the overall quality of their loans. Since the end of the financial crisis, the net change in bank credit standards has mostly fluctuated around zero indicating constant lending standards. While recently many concerns have been raised that the large increase in real estate prices in Germany could lead to a bubble on the property market, the bank lending survey suggests that credit standards with respect to household loans for real estate purchases have tightened over the last quarters due to a change in the lending law. From this perspective, it is unlikely that the overall quality of bank credits has deteriorated.

While there is little sign of an increase in bank risk-taking in terms of loan volume and loan quantity, the recent financial stability report by the Deutsche Bundesbank (2016) highlights one important variable which could be helpful to detect the build-up in banks' overall risk position namely the average interest rate fixation period. Even though it is not clear when interest rates rise again, an increase in refinancing cost could lead to some serious problems in the future if rates will stay low for an extended period of time. Recall the two key variables to contemporaneous bank income: banks' asset legacy and the NIM between long-term assets and short-term liabilities.

As shown in Figure 11, banks have on average increased the interest rate fixation period for households mortgage lending, which can be interpreted as an additional dimension of risk-taking since the maturity mismatch between long run assets and short run liabilities widens. While the share of variable or 1-year fixed interest rate contracts has declined, the share of contracts with more than 10-years fixed interest rates has increased strongly since 2014 from roughly $30 \%$ to almost 45\%. Recalling Figure 3, the increase in overnight deposits combined with the large share of long-term fix assets composes an interest rate risk which may only materialise in a few years.

\footnotetext{
${ }^{22}$ The bank lending survey is a quarterly survey among a representative sample of Euro Area banks. The questionnaire comprises 23 qualitative questions on past and expected future lending policies and is conducted by each national central bank.
} 
Figure 10: Overall Credit Standards of Loan Supply

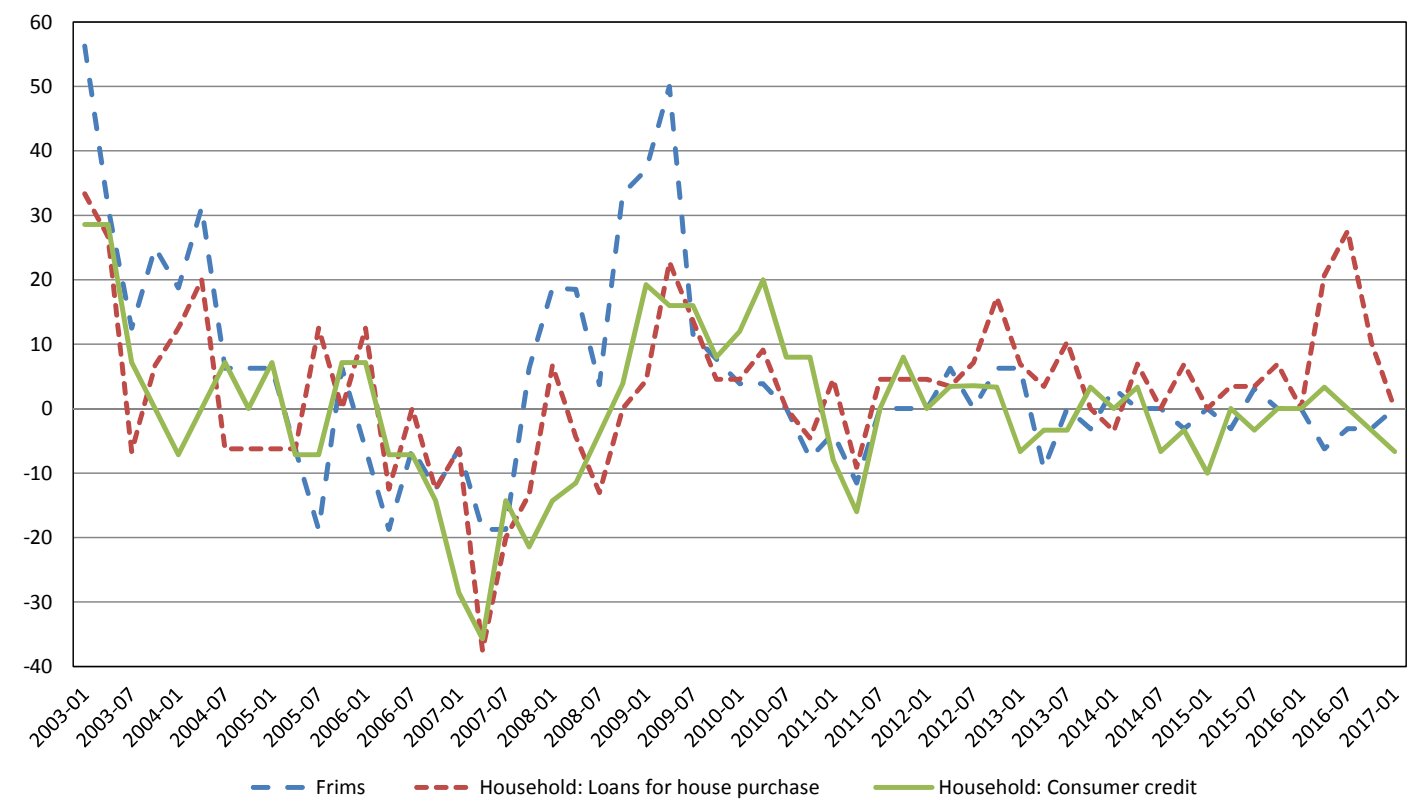

Source: Bundesbank Bank Lending Survey. Changes in the last three months as net percentage (frequency of tightened minus that of eased or reverse). Positive values indicate tightening of credit standards, negative values indicate a relaxation.

Figure 11: Households Lending for House Purchase by Interest Rate Fixation Period

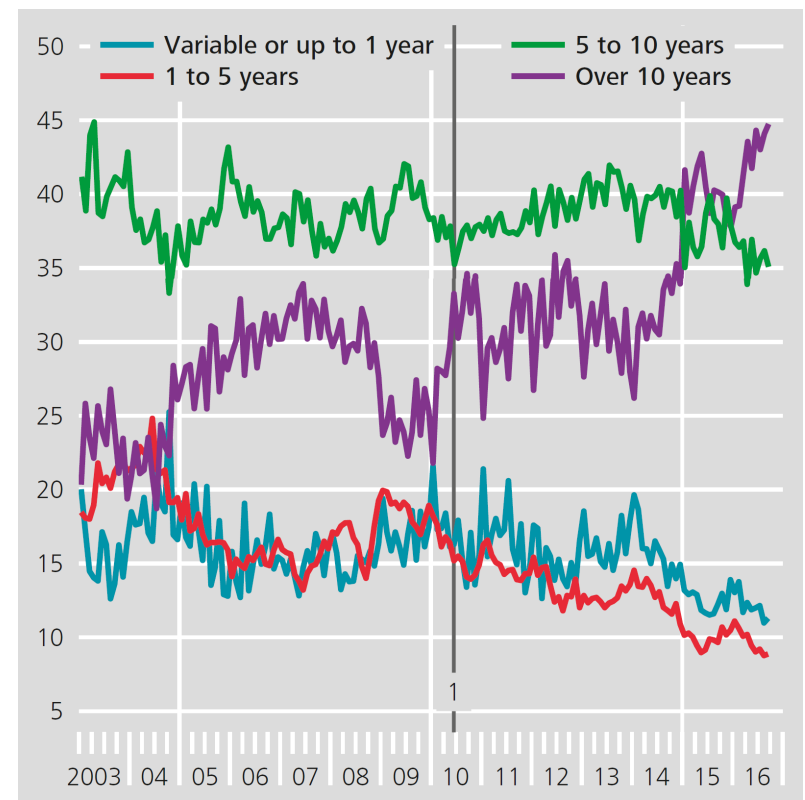

Source: Deutsche Bundesbank (2016) Financial Stability Report. As a percentage of new business, monthly. Within the Euro Area and including non-profit organisations serving households. Vertical line indicates change in the extrapolation since June 2010.

In other words, suppose a scenario where the ultra-low and negative interest rates prevail for a few more years, followed by a quick and unanticipated increase in short-term interest rates. If banks have mostly issued fix interest rate contracts during the years of the ultra-low period, their income in 
the following years is largely determined by these low interest contracts. In addition, a sudden and unexpected hike in short-term interests would lead to high refinancing costs and a large shrinkage in the NIM. Especially cooperative and savings banks are subject to heightened interest rate risk. The reason for this high risk is that these banks have seen the strongest increase in the share of overnight deposits and - unlike large international banks - cooperative and saving banks are usually not active on the capital and wholesale markets and do not hedge their positions with interest rates swaps ${ }^{23}$.

\section{Regression Analysis}

One essential advantage of micro level data is that it allows for a more detailed analysis beyond a simple average as, for example, some banks might have strongly reduced their credit growth rates while other could have strongly increased it leaving the average unaffected. This section first presents the baseline regression for the profit and loss statements with yearly observations using a fixed effect and System-GMM estimator. Second, a similar regression analysis measures the impact of unconventional monetary policy on bank leverage and loan growth rates again employing a FE and System-GMM estimator. As these two variables are based on monthly balance sheet data a slightly different specification can be used. Note the following for both cases: As the data set contains bank balance sheets, P\&L statements, and takes macroeconomic conditions as given, the analysis is entirely backward looking and does not capture any feedback effects of unconventional monetary policy on bank profitability and risktaking. Still, it provides important insights on how German banks have behaved during the first two and a half years of NIRP and QE policy measures.

A usual starting point for firm or bank level data is the fixed effects estimator in order to take the unobserved heterogeneity across entities into account. In the context of UMP measures, this would capture the unobserved time invariant characteristics of an individual bank. For example, this could be an individual bank's business model, which may be an important factor on how good or bad a bank can cope with negative interest rates and a flattening yield curve. However, in the case of yearly P\&L statements the estimator operates in a large $\mathrm{N}$, small $\mathrm{T}$ world where the FE estimator is subject to the Nickell-bias and the coefficients are downward biased relative to the true value. In contrast, the SystemGMM estimator, which was developed by the work of Blundell and Bond (1998) and Arellano and Bover (1995), should provide unbiased and consistent estimates in this environment. Given the data at hand, these are desirable features as the data set includes balance sheet and macroeconomic variables of which several display autoregressive behaviour. Moreover, balance sheet data can be subject to simultaneity which, however, should be alleviated by lagging these positions and defining the variables as endogenous in the System-GMM estimator.

Another debatable issue arises with respect to endogeneity of monetary policy in the sense that the

\footnotetext{
${ }^{23}$ Figure 14 and 15 show the average composition of the balance sheet of each bank group. Inter alia, the position "Other" includes financial derivatives. Following the Balance Sheet Modernisation Act in 2010, many large banks capitalised various financial derivatives while smaller banks typically do not hold such financial instruments.
} 
central bank's decision could be influenced by banks' profits or, more generally speaking, by financial stability considerations. However, this concern is somewhat eased by the fact that the data set is largely dominated by small German bank which individually are not key to the stability of the financial system. On the other hand, one German bank is listed among the globally systemic important financial institutions and does play a role for financial stability.

A critical assumption of the System-GMM estimator is that there is no autocorrelation in the in the idiosyncratic errors. Yet, due to first differencing the differenced errors have first order auto correlation by construction. This can be tested with the Arellano-Bond test under the $H_{0}$ of no first/ second order serial correlation, i.e. we $d o$ want to reject the test for first and do not want to reject the test for second order auto correlation of the errors. In addition, as the System-GMM estimator can easily employ a long list of (potentially irrelevant) instruments, the Sargan test is often employed to test for overidentification, assuming at least one of them is valid. Under the $H_{0}$ that all instruments are valid the null should not be rejected. Unfortunately, the Sargan test depends on homoscedasticity and does not work with a two-step estimator used in this paper. Nonetheless, it is still possible to manually limit the number of instruments employed ${ }^{24}$.

As the Sargan Test for the one-step estimator provided evidence that the instruments are valid ${ }^{25}$, the System-GMM estimator is next specified as a two-step estimator, i.e. the inverse of the covariance matrix of the moment vector from the first-step estimation is used in a second step as the weighting matrix. Also, the standard errors are computed as robust standard errors using the estimator developed by Windmeijer (2005). In the case of the FE estimator, standard errors are clustered by bank entities allowing for intra-bank correlation. In order to assess the average impact of the interest rate level and the slope of the yield curve on different income components, the following baseline regression is run:

$$
\begin{aligned}
y_{i, t} & =\alpha y_{i, t-1}+\beta_{1} \text { level }_{t}+\beta_{2} \text { level }_{t}^{2}+\beta_{3} \text { slope }_{t} \\
& +\phi \text { deposit ratio }{ }_{i, t} \text { level }_{t}+\varphi \text { deposit ratio } \\
i, t & \mathrm{UMP}_{t} \text { level }_{t} \\
& +\gamma Z_{t-1}+\theta X_{i, t-1}+v_{i}+u_{i, t}
\end{aligned}
$$

where $y_{i, t}=\frac{Y_{i, t}}{\mathrm{Avg} . \mathrm{TA}_{t}}$ denotes the dependent variables which are: net interest income, net income from commissions, and net income from the valuation of assets and provisions each calculated in basis points relative to total average asset in year $t$. Due to the introduction of fair value accounting in late 2010, a structural break strongly affects the net income from trading. Therefore, for this variable the data set is split accordingly (see below).

The most relevant explanatory variables are the $\mathrm{level}_{t}$ of short-term interest rate (three month Euribor rate), the slope ${ }_{t}$ of the yield curve (ten year German Bund - three month Euribor) and the interaction term. To capture potential non-linearities, the squared value of the level $t_{t}$ of the interest

\footnotetext{
${ }^{24}$ If not stated differently, the maximum number of lags used as instruments for the System-GMM estimator is capped at three in the following analysis.

${ }^{25}$ Results for the one step estimator are omitted here for brevity.
} 
rate is also taken into account. While both the level and the slope are affected by unconventional monetary policy in general, the former should mostly be influenced by the ECB's choice of setting the short-term refinancing and deposit rate (NIRP), whereas the latter is thought to be determined by the ECB's large scale asset purchase programme (QE). A second important aspect of this paper is the potential heterogeneity of banks in times of unconventional monetary policy. The interaction term deposit ratio $_{i, t} \cdot \mathrm{level}_{t}$ is included to take this heterogeneity into account. The central idea behind this approach is that at negative levels of the short-term interest rate there could be a stronger relationship between the share of deposits and different income components. More precisely, breaking through the ZLB could make expansionary monetary policy contractionary in particular for those banks with higher deposit ratios as a source of funding. Thus, to differentiate between average times and unconventional monetary policy by the ECB, one interaction term is multiplied with the dummy $\operatorname{UMP}_{t}(=1$ from 2014 to 2016$)^{26}$.

Furthermore, to account for bank specific effects $X_{i, t-1}$ denotes a set of bank explanatory variables. These variables are bank size (log of total assets), the leverage ratio (CET1 to total assets), bank efficiency (cost-to-income ratio), bank loan ratio (non-bank loans to total assets), and the deposit ratio (overnight deposits to total liabilities) each lagged by one period to mitigate concerns of endogeneity. Additionally, $Z_{t-1}$ represents a set of macro explanatory variables which are the same to all banks $i$. These are the year on year German GDP growth rate, the log of the yearly average of the German DAX index, and a yearly house price index. Finally, $v_{i}$ denotes the unobserved time invariant individual fixed effect and $u_{i, t}$ is the idiosyncratic error term. The same baseline specification is used for the System-GMM estimator.

Also, to differentiate between different bank groups, separate regressions for large banks (Major banks, Landesbanken, and cooperative central banks), small banks (cooperative and savings banks), and regional banks are $\operatorname{run}^{27}$. Note that for the group of small and regional banks the System-GMM estimator is employed. In contrast, for large banks the System-GMM estimator cannot be calculated as the $\mathrm{N}$ dimension is reduced to only 15 banks. Also, as argued in section 3 the group of large banks is subject to the structural break due to the Balance Sheet Modernisation Act in 2010. Thus, only a subset from 2010 onwards is taken into account for this group of banks. Unfortunately, since only six years are left this makes it harder to differentiate between average before and after UMP measures and the interaction term gets automatically omitted because of collinearity in the time dimension ${ }^{28}$.

The results for the regressions on net interest income can be found in Table 3. First of all, note that most coefficients have the anticipated sign. There is a positive and concave relationship between the level of short-term interest rates and bank income indicating that banks on average have higher net interest earnings when short-term interest rates are higher. However, this finding is only weakly significant. The

\footnotetext{
${ }^{26}$ The same results were obtained when directly differentiating between before and after going negative. In this case, the two interaction were specified as deposit ratio ${ }_{i, t} \mathrm{UMP}_{t} \mathrm{level}_{t}$ and deposit ratio ${ }_{i, t}\left(1-\mathrm{UMP}_{t}\right) \mathrm{level}_{t}$. These results are available upon request.

${ }^{27}$ The group of other banks was also tested. However, as this group of bank has predominately long-term obligations and the results were mostly insignificant, they are omitted here.

${ }^{28}$ Also, for the group of large banks the DAX explanatory variable is dropped automatically due to collinearity. The variation across bank entities is simply too small, which also makes time dummies superfluous as they are largely dropped automatically.
} 
only exception is the group of large banks which is arguably a special case due to few observations as outlined above. Regarding the slope of the yield curve, all estimators show the anticipated positive relation which is in line with the maturity transformation of banks. On the other hand, the mostly negative sign of the estimated coefficients for GDP growth and the house prices seems surprising. In the case of house prices, a possible explanation for this is the inverse relationship between interest rates and asset prices. If interest rates are low, usually house prices increase as currently observed in Germany. Also, a low interest rate correlates in general with lower net interest income as suggested by the level coefficient.

Turning to bank specific effects and the interaction term, while in general there is a positive relationship between the level of short-term interest rates and net interest income, the interaction term suggests that during UMP banks with a higher share of deposits profit more when the interest rate level is higher. More intuitively, this positive relation implies that high deposit banks face lower net interest income when interest rates are lower. Importantly, this relationship becomes only relevant when breaking through the ZLB as the coefficient of the interaction term gets higher and significant for UMP but not for the total average interaction term. A stylised graphical interpretation of this result can be found in the Appendix in Figure 19. Also note that this result seems to be driven by the smaller banks, which usually have a higher share of deposits and are more dependent on interest income. In addition, the coefficient of the deposit share is mostly negative, indicating that on average banks with more overnight deposits have fewer net interest income. However, the magnitude of this effect is still small. In other words, the results suggest that once setting the short-term interest rate to negative levels banks have slightly lower net interest income and this effect intensifies for banks with higher deposit ratios.

The results for net commissions are shown in Table 4. It is important to note that this position in the P\&L captures all fees and commissions paid or collected by the bank. Therefore, in addition to the previous estimation the log of the DAX index is included. The estimations yield a negative and significant relationship between the log of the DAX and net commission income. This could be driven by the fact that brokerage commissions have decreased over the last decade following increased competition and technological advancement, whereas the DAX has increased over the same period ${ }^{29}$. In contrast, there exists a positive relation between housing prices, which are typically a more local brokerage service, and commission income. However, the relationship regarding the interaction term is less clear. While it is positive and mostly significant during the years of negative interest rates it is not clear if banks with more or less deposit benefit as the deposit ratio coefficient is only negative and significant for the subset of small banks. This suggests that following negative interest rates small banks with larger deposits find it harder to raise commission income, which does not support the argument that banks could simply increase their fees to pass on negative interest rates.

The next variable of interest is the net income or the net charges from the valuation of assets, which primarily includes write downs/ups for assets, any loan loss provisions, and the reversals of loan loss

\footnotetext{
${ }^{29}$ The alternative of taking DAX volatility does not change this result.
} 
provisions. The result can be found in Table 5. The coefficient for the level of the interest rates indicates that at higher levels of interest rates more loan loss provisions are needed (a cost factor) since the interest burden is higher. Given the positive interaction term and the positive value of the deposit ratio, we can conclude that in this case it is actually more beneficial to have a higher share of deposits. However, the coefficient for the interest level is much higher compared to the interaction term, suggesting that it only plays a minor role. Moreover, in this regression the GDP growth rate has the anticipated sign that higher growth rates are correlated with fewer write down and more reversals of loan loss provisions.

As already noted above, the case of net trading income is special because fair value accounting was only introduced into German accounting law in late 2010. Therefore, for the regressions on net trading income the sample is split and starts only in 2010 which makes it harder to differentiate between before and after the introduction of negative interest rates. Thus, the baseline regression is changed to

$$
\begin{aligned}
y_{i, t} & =\alpha y_{i, t-1}+\beta_{1} \text { level }_{t}+\beta_{2} \text { level }_{t}^{2}+\beta_{3} \text { slope }_{t} \\
& +\phi \text { DAX }_{t} \text { trading book assets } \\
i, t & +\varphi \text { DAX }_{t} \text { trading book liabilities } \\
i, t & \\
& +\gamma Z_{t-1}+\theta X_{i, t-1}+v_{i}+u_{i, t}
\end{aligned}
$$

with additional bank specific control variable introduced, which are the share of the asset and the liability trading book. Also, two interaction terms between the size of the two trading books and the DAX are included. Table 6 in the Appendix presents the outcome of this regression. Not surprisingly, as only a few German banks are active on the trading markets on a larger scale the bank specific explanatory variables are usually close to zero and insignificant. Not even the size of the trading book has a significant or sizeable impact on trading income. The only variables which seem to play a role are the macro explanatory variables, which all have the anticipated sign.

Admittedly, one potential concern with this approach is that the identification of UMP is to some degree ad hoc via a time dummy. Using a slightly different specification as in Equation (3), a similar regression is run which proxies the strength of UMP by specifying the interaction term as the deposit share multiplied with the difference between the level of the 3 month Euribor and the implied shadow rate.

$$
\begin{aligned}
y_{i, t} & =\alpha y_{i, t-1}+\beta_{1} \text { level }_{t}+\beta_{2} \text { level }_{t}^{2}+\beta_{3} \text { slope }_{t} \\
& +\phi \text { deposit ratio } \text { rat }_{i, t} \cdot \text { UMP strength } \\
& +\gamma Z_{t-1}+\theta X_{i, t-1}+v_{i}+u_{i, t} .
\end{aligned}
$$

As pointed out by Wu and Xia (2017), the various unconventional actions taken by ECB lead to a much lower implicit policy rate, the so-called shadow rate. Therefore, taking the difference between these two should provide a crude estimate for the strength of UMP ${ }^{30}$. Notwithstanding, the unconventional policy actions by the ECB also push the Euribor downwards to the lower bound of the deposit facility.

\footnotetext{
${ }^{30}$ See Figure 20 in the Appendix for a graphical illustration.
} 
Hence, taking the difference between these two is a conservative estimate as the total strength of UMP is likely to be higher. Moreover, as the P\&L variables are on a yearly basis, this difference is averaged across each year making it even cruder. Still, the results of this estimation, which can be found in the Appendix in Table 7, 8, and 9, hint in the same direction as the regression based on a simple dummy identification. The stronger UMP measures the weaker average net interest income which intensifies for higher deposit ratios.

Having examined bank profitability in greater detail, the changes in bank risk-taking in terms of loan growth and leverage ratio are considered next. According to the risk-taking channel, banks could be induced to take more risk if interest rates are too low for too long. A potential reason for such behaviour could be limited liability considerations. However, as we have already seen in Section 4, on average banks have only moderately increase loan growth rates and increased their leverage ratio due to the Basel III regulations ${ }^{31}$.

As the leverage and the loan growth rates are taken solely from bank balance sheet data, which are on a monthly basis, the Nickell bias decreases due to the higher $\mathrm{T}$ dimension and the fixed effects estimator should in principle provide unbiased estimates. Therefore, in the following all bank group regressions are based on the fixed effects estimator while the results for the System-GMM estimator are still included as a robustness check. Moreover, as the difference between the Euribor and the shadow rate can be calculated on a monthly basis this variable is taken as the main indicator for UMP. Note that the baseline regression with a dummy was also run leading to similar results ${ }^{32}$. All control variables are now based on monthly observations with the exception of the GDP growth rate which is quarterly.

The estimation results for the leverage ratio are summarised in Table 10. The interaction term between the strength of UMP and the deposit ratio suggests a negative relationship between unconventional monetary policy measures and leverage ratio with a mostly positive coefficient for the deposit ratio. In other words, the stronger the unconventional monetary policy measures the lower leverage ratio especially for those banks with higher deposits. This does indeed indicate that high deposit banks have increased their risk-taking in terms by reducing their leverage ratio. However, note that the magnitude of the coefficient is quiet small and that most banks in total increase their leverage ratio due to the new Basel regulations as outlined before. Put differently, this can be interpreted that banks with high deposit ratios must have reduced their voluntarily capital holdings relative to the increased required capital holdings applying to all the banks.

\footnotetext{
${ }^{31}$ In the current version of the paper, I do not explicitly control for the changes in the Basel III regulations. Despite the fact that the Basel III regulations undoubtedly have an effect on bank risk taking, it is not straight forward to control for these regulatory changes. A simple approach would be to introduce a dummy since the start of the Basel III regulations. However, this approach would be flawed for two main reasons. First of all, Basel III is not a structural break in the classic sense. In the European Union, most regulatory changes were decided in 2013. However, while these changes came into force from 2014 onwards banks were given several years to adjust to the new requirements. Therefore, some banks might have adjusted early whereas other bank could have waited longer. Second, such a dummy would very much overlap with the time frame of UMP making it unclear which effects are actually captured. Currently, I am trying to acquire additional data from the Bundesbank to create a distance to Basel III variable. If one, for instance, would look at the actual risk weighted tier one core equity ratio relative to the ratio a bank should have under the Basel III rules, it might be possible to calculate the difference between these two and to interpret the gap as the regulatory adjustment pressure.

${ }^{32}$ They are omitted here for brevity but are available upon request.
} 
Finally, considering the impact of unconventional monetary policy on year on year loan growth rates Table 11 suggests that stronger unconventional monetary policy correlates with lower loan growth rates for banks with higher deposits. While it is true that on average the German banking sectors has experienced positive loan growth rates, this micro view indicates that there has been a reshuffling of loans from high deposit banks to low deposit banks. This is an important finding as it indicates that the monetary policy pass-through is potentially jeopardised for these banks at negative policy rates. Consistent with early findings, smaller banks which typically have a higher share of overnight deposits find it harder to pass on negative rates to their customers. As a consequence they reduce their loan rates and expansionary monetary policy becomes contractionary.

\section{Robustness}

As an additional robustness check, I follow the approach by Heider et al. (2017) and Eggertsson et al. (2017). Assuming that going negative is indeed a "game changer" employing a difference-in-difference estimator should provide a consistent and unbiased estimate given some underlying assumptions. The average change for banks with high deposit ratios (treatment group) could be different at negative rates relative to banks with low deposits (control group) as for these high deposit banks the monetary passthrough might break down at negative rates. Formally, the diff-in-diff reads as

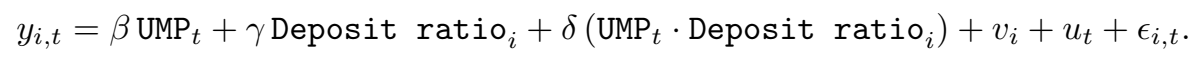

To differentiate between the treated and the untreated banks, first note that the average overnight deposit ratio in the data set is at $35 \%$ (see also the histogram of overnight deposits in Figure 21 in the Appendix). Therefore, high deposit banks are defined as banks with a deposit ratio of more than $35 \%$ (Deposit ratio $=1$ ) whereas low deposit banks are defined as banks with a lower deposit ratio (Deposit ratio $=0$ ). Alternative specifications of taking "other banks" (with primarily long-term deposits) as the control group, or of taking the upper 75 percentile vs. the lower 25 percentile of the average bank deposit ratio, yield the same qualitative result.

Following the literature, for monthly balance sheet data a time frame of 2013 to 2015 is chosen ${ }^{33}$. The time dummy is set to be equal to one starting from June 2014 when the deposit facility was first lowered to negative levels (UMP $=1$ ). Hence, there are roughly one and a half years before and after the treatment. In contrast, when working with yearly P\&L data, I allow for a longer time period from 2012 to 2016 giving two observations before the treatment and three afterwards for each bank. As an alternative starting point of negative rates (May) 2015 was chosen when the Euribor entered into negative territory which, however, leaves the main result unaffected. Also, in order to control for unobserved heterogeneity across banks entities or across time, bank fixed $v_{i}$ and time fixed $u_{t}$ effects are introduced in the estimations.

\footnotetext{
${ }^{33}$ While there is no formal test for the diff-in-diff estimator I run out of sample tests from 2005 to 2007 for monthly and from 2003 to 2007 for yearly data to find insignificant results.
} 
All remaining influences are captured by the error term $\epsilon_{i, t}$.

The results for the two main variables of interest (net interest income and loan growth) are shown below in Table 12 and $13^{34}$. The results from these estimations hint in the very same direction as the results shown in the previous section. Once interest rates become negative banks with larger deposits have on average a lower net interest income. Also, banks with an above average deposit ratio have decreased their loan growth rates relative to low deposit banks.

\section{Conclusion}

Since the announcement of a negative interest rate policy and a quantitative easing programme by the ECB, the German banking sector exhibited a huge short-term over-funding. However, despite what many commentators have feared the good news from the evidence given in this paper suggests that the German banking sector performed reasonably well during the first years of unconventional monetary policy. Banks so far have not faced a huge cost burden from negative interest rates. Rather, banks have benefited from lower refinancing costs and shrinking loan loss provisions. In fact, profits across all banking groups have so far been only mildly affected by NIRP and the QE programme. Furthermore, there is only little evidence that German banks have engaged in excessive risk-taking by granting too much credit or by lowering their lending standards in response to interest rates being too low for too long.

On the other hand, the bad news is that the often mentioned capital gains from asset holdings play little role for German banks, due to the conservative German accounting rules. Only some larger banks with a sizeable trading portfolio may have profited from this income source whereas it is practically irrelevant for all other banks. Also, the hypothesis that banks can increase their fees and commission to pass on negative interest rates to their customers does not hold. Even though several banks did increase their fees, this additional income is usually a flat rate and not proportional. Hence, it is merely a drop in the ocean relative to total assets. Moreover, banks on average were neither able to push off large amounts of excess funding nor to substitute deposit financing with wholesale funding. While a few banks might have found creative ways to escape increasing short-term liabilities, the banking system as a whole has no way to do so. In fact, the average share of overnight private deposits increased since 2013 from about $30 \%$ to $45 \%$ of total assets for smaller banks. Even major banks exhibited a mild increase from roughly $10 \%$ to $15 \%$ of total assets over the same period. In addition, especially high deposit banks have on average a lower net interest income and they slightly decreased their leverage ratio.

While the magnitude of these negative effects is still small, one should be careful in concluding that negative interest rate transmit just like positive rates do and that there are no risks associated to these UMP measures. In fact, the ugly truth is that if interest rates remain on their current level and the yield curve keeps on flattening, banks must be adversely affected at some tipping point due to their intrinsic

\footnotetext{
${ }^{34}$ Moreover, estimations on the other indicators discussed in this paper were also run but mostly yield insignificant results. They are available upon request.
} 
business model and the expansionary monetary policy stance becomes contractionary eventually. A clear indicator for this is that banks with high deposit ratios have already decreased their lending.

Moreover, the financial stability report from the Deutsche Bundesbank (2016) highlights an import additional source of risk-taking which is currently under-explored in the literature. The more extensive bank maturity transformation together with rising deposit ratios exposes banks to an increasing interest rate risks especially under a scenario of a fast and unexpected rise in short-term interest rates. As savings and cooperative banks typically do not hold any derivatives to hedge their position, these banks are in particular subject to this interest rate risk. A thorough examination of this finding is left for future research. 


\section{References}

Adrian, T. and Shin, H. S. (2010): "Financial intermediaries and monetary economics". Federal Reserve Bank of New York, Staff Report 2010(398).

Ahtik, M., Banerjee, B., and Remsak, F. (2016): "Net interest margin in a low interest rate environment: Evidence for Slovenia". Bancni vestnik (The Journal for Money and Banking) 65(11), pp. 77-89.

Alessandri, P. and Nelson, B. D. (2015): "Simple banking: Profitability and the yield curve". Journal of Money, Credit and Banking 47(1), pp. 143-175.

Altavilla, C., Boucinha, M., and Peydró, J.-L. (2014): "Monetary policy and bank profitability in a low interest rate environment". ECB Working Paper Series (2105).

Arellano, M. and Bover, O. (1995): "Another look at the instrumental variable estimation of errorcomponents models". Journal of Econometrics 68(1), pp. 29-51.

Basten, C. and Mariathasan, M. (2018): "How banks respond to negative interest rates: Evidence from the Swiss exemption threshold". CESifo Working Paper Series (6901).

Beatty, A. and Liao, S. (2014): "Financial accounting in the banking industry: A review of the empirical literature". Journal of Accounting and Economics 58(2-3), pp. 339-383.

Bech, M. L. and Malkhozov, A. (2016): "How have central banks implemented negative policy rates?" BIS Quarterly Review 2016(March).

Blundell, R. and Bond, S. (1998): "Initial conditions and moment restrictions in dynamic panel data models". Journal of Econometrics 87(1), pp. 115-143.

Bolt, W. et al. (2012): "Bank profitability during recessions". Journal of Banking and Finance 36(9), pp. $2552-2564$.

Borio, C. and Gambacorta, L. (2017): "Monetary policy and bank lending in a low interest rate environment: Diminishing effectiveness?" Journal of Macroeconomics, pp. 1-15.

Borio, C., Gambacorta, L., and Hofmann, B. (2017): "The influence of monetary policy on bank profitability". International Finance 20(1), pp. 48-63.

Borio, C. and Zhu, H. (2012): "Capital regulation, risk-taking and monetary policy: A missing link in the transmission mechanism?" Journal of Financial Stability 8(4), pp. 236-251.

Brunnermeier, M. K. and Koby, Y. (2017): "The reversal interest rate: The effective lower bound of monetary policy". mimeo 2017(July).

Busch, R. and Memmel, C. (2015): "Banks' net interest margin and the level of interest rates". Bundesbank Discussion Paper 2015(16). 
Busch, R. and Memmel, C. (2016): "Quantifying the components of the banks' net interest margin". Financial Markets and Portfolio Management 30(4), pp. 371-396.

Cœuré, B. (2016): "Assessing the implications of negative interest rates". Speech at the Yale Financial Crisis Forum, Yale School of Management, New Haven, 28.07.2016.

Dell'Ariccia, G., Laeven, L., and Marquez, R. (2014): "Real interest rates, leverage, and bank risk-taking". Journal of Economic Theory 149(1), pp. 65-99.

Dell'ariccia, G., Laeven, L., and Suarez, G. A. (2017): “Bank leverage and monetary policy's risk-taking channel: Evidence from the United States". Journal of Finance 72(2), pp. 613-654.

Demertzis, M. and Wolff, G. B. (2016): "What impact does the ECB's quantitative easing policy have on bank profitability?" Bruegel Policy Contribution 2016(20).

Demiralp, S., Eisenschmidt, J., and Vlassopoulos, T. (2017): "Negative interest rates, excess liquidity and bank business models: Banks reaction to unconventional monetary policy in the Euro Area". mimeo 2017(May).

Deutsche Bundesbank (2016): "Financial stability review". Deutsche Bundesbank.

Dombret, A., Gündüz, Y., and Rocholl, J. (2017): "Will German banks earn their cost of capital?" Bundesbank Discussion Paper 2017(01).

Drechsler, I., Savov, A., and Schnabl, P. (2017): "The deposits channel of monetary policy". The Quarterly Journal of Economics 132(4), pp. 1819-1876.

Eggertsson, G. B., Juelsrud, R., and Wold, E. G. (2017): "Are negative nominal interest rates expansionary?" NBER Working Paper Series 2017(24039).

English, W. B. (2002): "Interest rate risk and bank net interest margins". BIS Quarterly Review 2002(10), pp. $67-82$.

English, W. B., Heuvel, S. den, and Zakrajsek, E. (2014): "Interest rate risk and bank equity valuations". University of Pennsylvania, Working Paper Series 2014(05).

Harhoff, D. and Körting, T. (1998): "Lending relationships in Germany: Empirical rvidence from survey data". Journal of Banking and Finance 22, pp. 1317-1353.

Heider, F., Saidi, F., and Schepens, G. (2017): "Life below zero: Bank lending under negative policy rates". mimeo 2017(May).

Ioannidou, V., Ongena, S., and Peydró, J. L. (2015): "Monetary policy, risk-taking, and pricing: Evidence from a quasi-natural experiment". Review of Finance 19(1), pp. 95-144. 
Jiménez, G. et al. (2014): "Hazardous times for monetary policy: What do twenty-three million bank loans say about the effects of monetary policy on credit tisk-taking?" Econometrica 82(2), pp. 463505.

Jobst, A. and Lin, H. (2016): "Negative interest rate policy (NIRP): Implications for monetary transmission and bank profitability in the Euro Area". IMF Working Papers 2016(172).

Jordan, T. (2016): "Monetary policy using negative interest rates : A status report". Speech, Swiss National Bank 2016(October).

Kerbl, S. and Sigmund, M. (2017): "Negative interest rates: Forecasting banks ' profitability in a new environment". International Journal of Forecasting (Forthcoming).

Lambert, F. and Ueda, K. (2014): "The effects of unconventional monetary policies on bank soundness". IMF Working Papers 2014(152).

Maddaloni, A. and Peydró, J.-L. (2011): "Bank risk-taking, securitization, supervision, and low interest rates: Evidence from the Euro Area and the US lending standards". The Review of Financial Studies $24(6)$, pp. 2121-2165.

Riksbank (2015): "Monetary policy report - February 2015”. 2015(February).

Rognlie, M. (2016): "What lower bound? Monetary policy with negative interest rates". mimeo 2016(July).

Scheiber, T., Silgoner, M. A., Stern, C., et al. (2016): "The development of bank profitability in Denmark, Sweden and Switzerland during a period of ultra-low and negative interest rates". Focus on European Economic Integration 2016(Q3).

Stein, J. C. (2014): "Incorporating financial stability considerations into a monetary policy framework". Speech at the International Research Forum on Monetary Policy, Washington, D.C., March 21, 2014.

Svensson, L. E. O. (2015): "Monetary policy and macroprudential policy: Different and separate". mimeo 2015(February).

The Basel Committee (2011): "Basel III: A global regulatory framework for more resilient banks and banking systems". Bank for International Settlements.

Windmeijer, F. (2005): "A finite sample correction for the variance of linear efficient two-step GMM estimators". Journal of Econometrics 126(1), pp. 25-51.

Wu, J. C. and Xia, F. D. (2017): "Time-varying lower bound of interest rates in Europe". Chicago Booth Research Paper 2017(06). 


\section{Appendix}

Table 2: List of Variables

\begin{tabular}{l|l}
\hline Monthly balance sheet statistics & Source: \\
\hline Total assets & Bundesbank \\
Cash in hand & Bundesbank \\
Balances with central banks & Bundesbank \\
T-bills and similar debt instruments & Bundesbank \\
Loans to banks & Bundesbank \\
Loans to non-banks & Bundesbank \\
$\quad$ Loans to households & Bundesbank \\
\multicolumn{1}{l}{ Loans to firms } & Bundesbank \\
\multicolumn{1}{c}{ Debt instruments } & Bundesbank \\
Bonds and notes & Bundesbank \\
Shares and other variable-yield securities & Bundesbank \\
Trading portfolio (assets) & Bundesbank \\
Total liabilities & Bundesbank \\
Capital & Bundesbank \\
Liabilities to banks & Bundesbank \\
Liabilities to non-banks & Bundesbank \\
Securitised liabilities & Bundesbank \\
$\quad$ Fiduciary liabilities & Bundesbank \\
$\quad$ Provisions for liabilities and charges & Bundesbank \\
Trading portfolio (liabilities) & Bundesbank \\
\hline Yearly banks' profit and loss statements & Bundesbank \\
\hline Net interest received/ paid & Source: \\
Net commissions received/ paid & Bundesbank \\
Staff costs & Bundesbank \\
Total administrative spending & Bundesbank \\
Net profit/ loss from trading portfolio & Bundesbank \\
Net income/ charges from valuation of assets & Bundesbank \\
Other and extraordinary income & Bundesbank \\
Gross earnings & Bundesbank \\
Operating profit & Bundesbank \\
Profit before tax & Bundesbank \\
Taxes paid & Bundesbank \\
Profit after tax & Bundesbank \\
\hline Additional control variables & Bundesbank \\
\hline Real German GDP growth & Source: \\
EURIBOR, 3m & German Federal Statistic Office \\
German Bund, 10 y & Datastream \\
Stock market: DAX, log & Datastream \\
House price index & Datastream \\
ECB shadow rate & German Federal Statistic Office \\
\hline & Wu and Xia (2017) \\
\hline
\end{tabular}

Note: Several of the balance sheet variables are also available at sub aggregates, which are e.g. divided into regions (domestic, Euro Area, non-Euro Area) or maturity (overnight, up to 1 year, 2 to 5 years, etc.). For more details about the balance sheet statistic or the P\&L statements please see the Bundesbank website. 
Figure 12: Average Total Assets Over Time
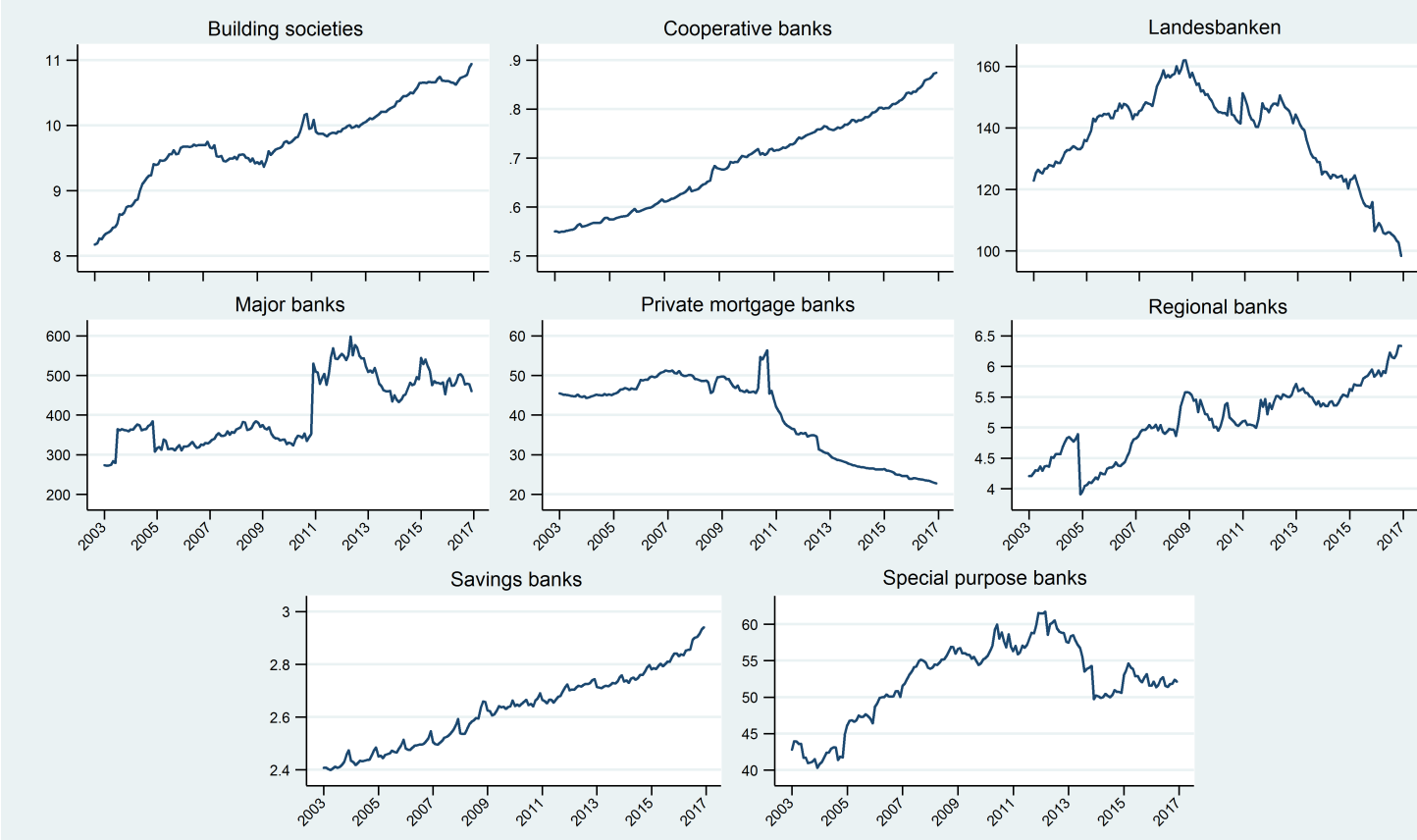

\section{Average total assets}

Source: Bundesbank balance sheet statistics. In billion EUR.

Figure 13: Number of Mergers and Average Bank Income
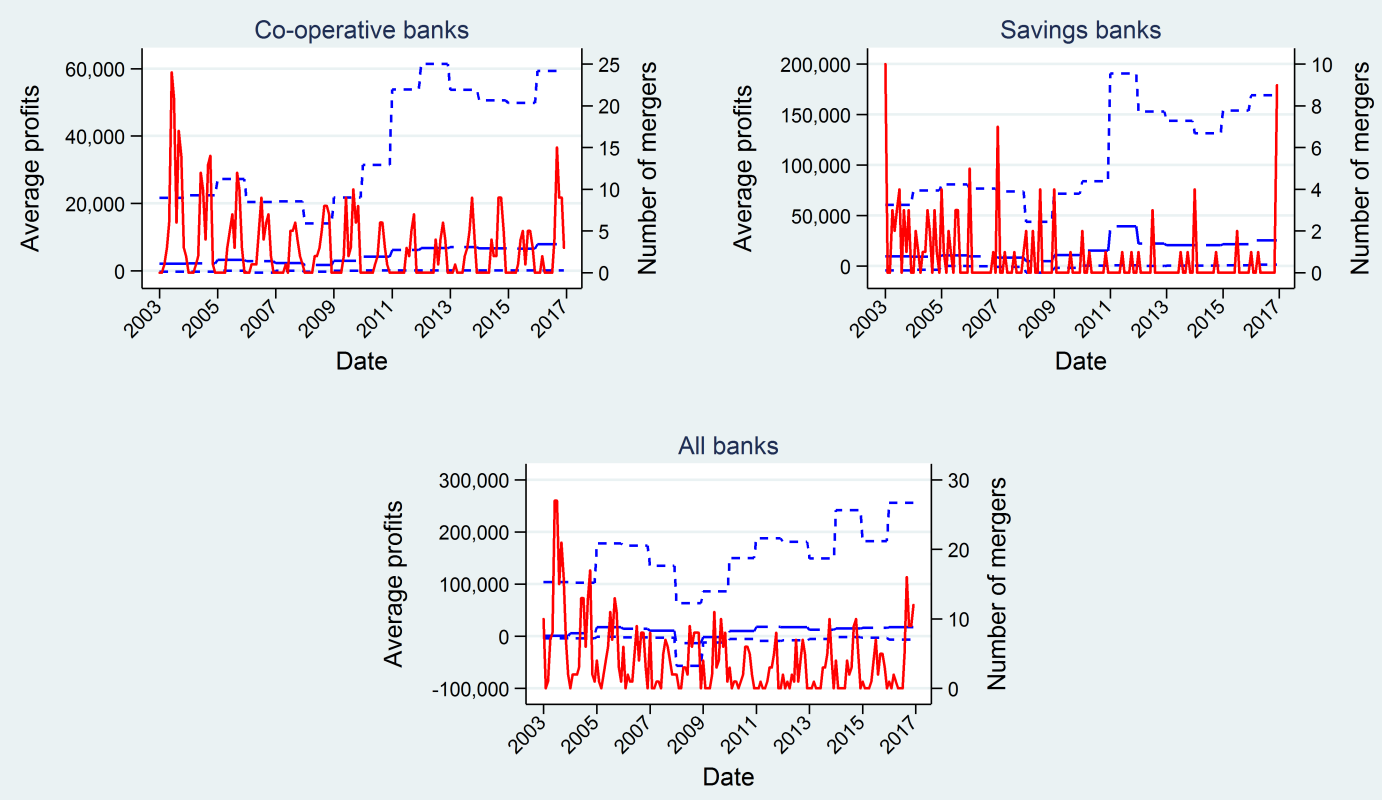

-- Average profits

-

-

Number of Mergers

Source: Bundesbank. Own calculations. Number of mergers is summed over each month. 
Figure 14: Average Composition of Total Assets Over Time
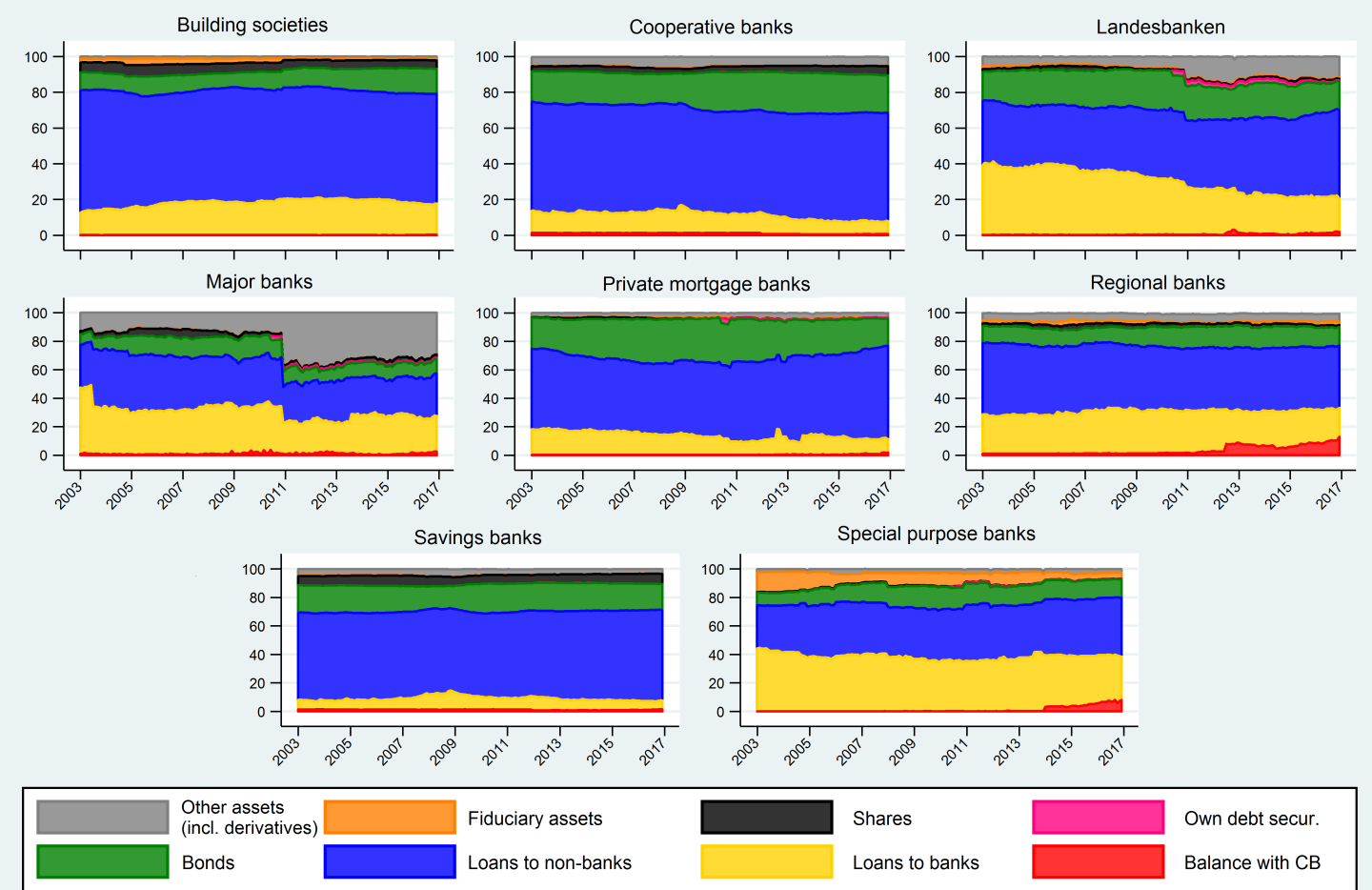

Source: Bundesbank Bank Balance Sheet Statistics. Own calculations. In percentage relative to total assets

Figure 15: Average Composition of Total Liabilities Over Time

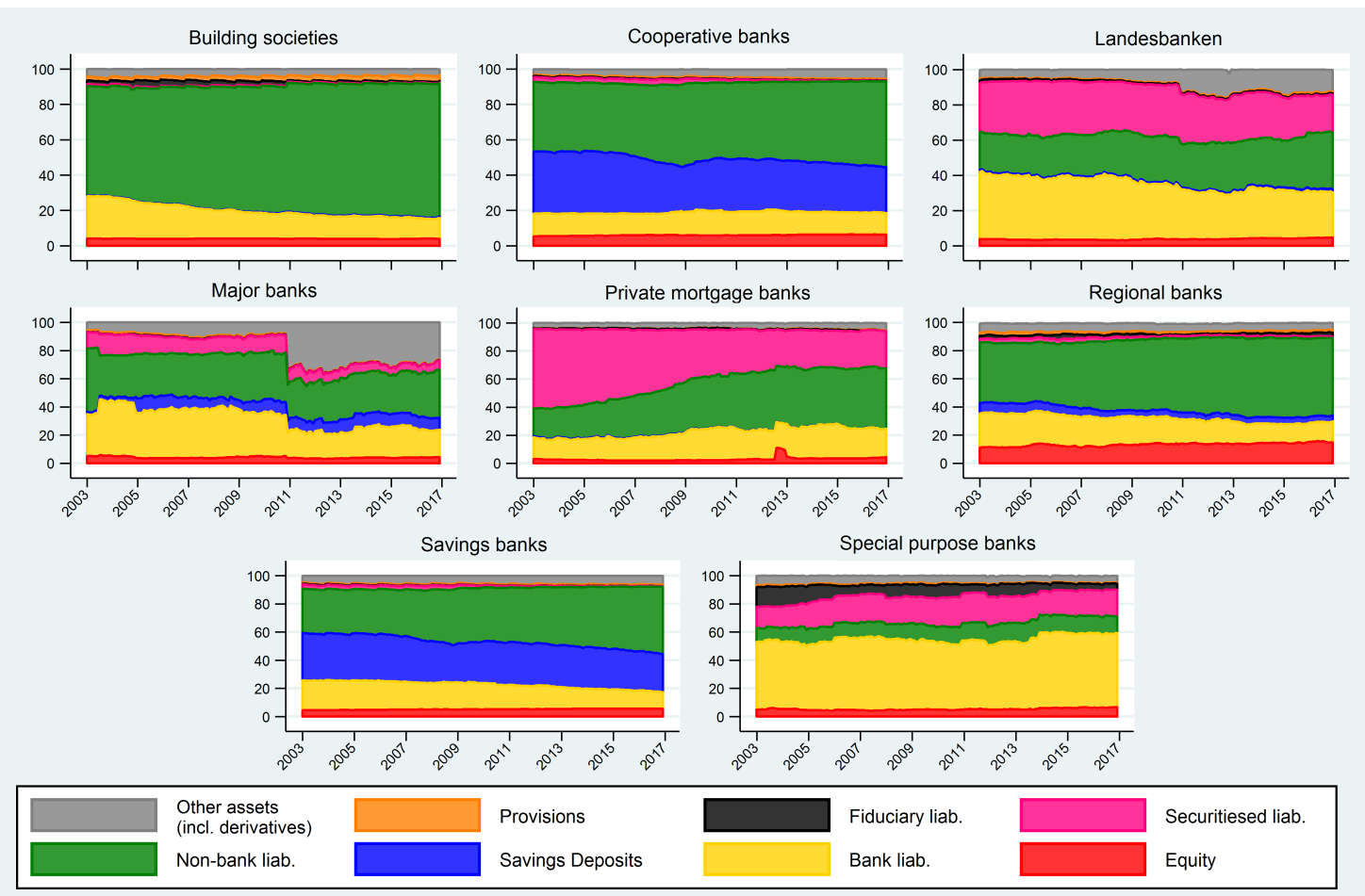

Source: Bundesbank Bank Balance Sheet Statistics. Own calculations. In percentage relative to total liabilities 
Figure 16: Total Income from Interest and Trading

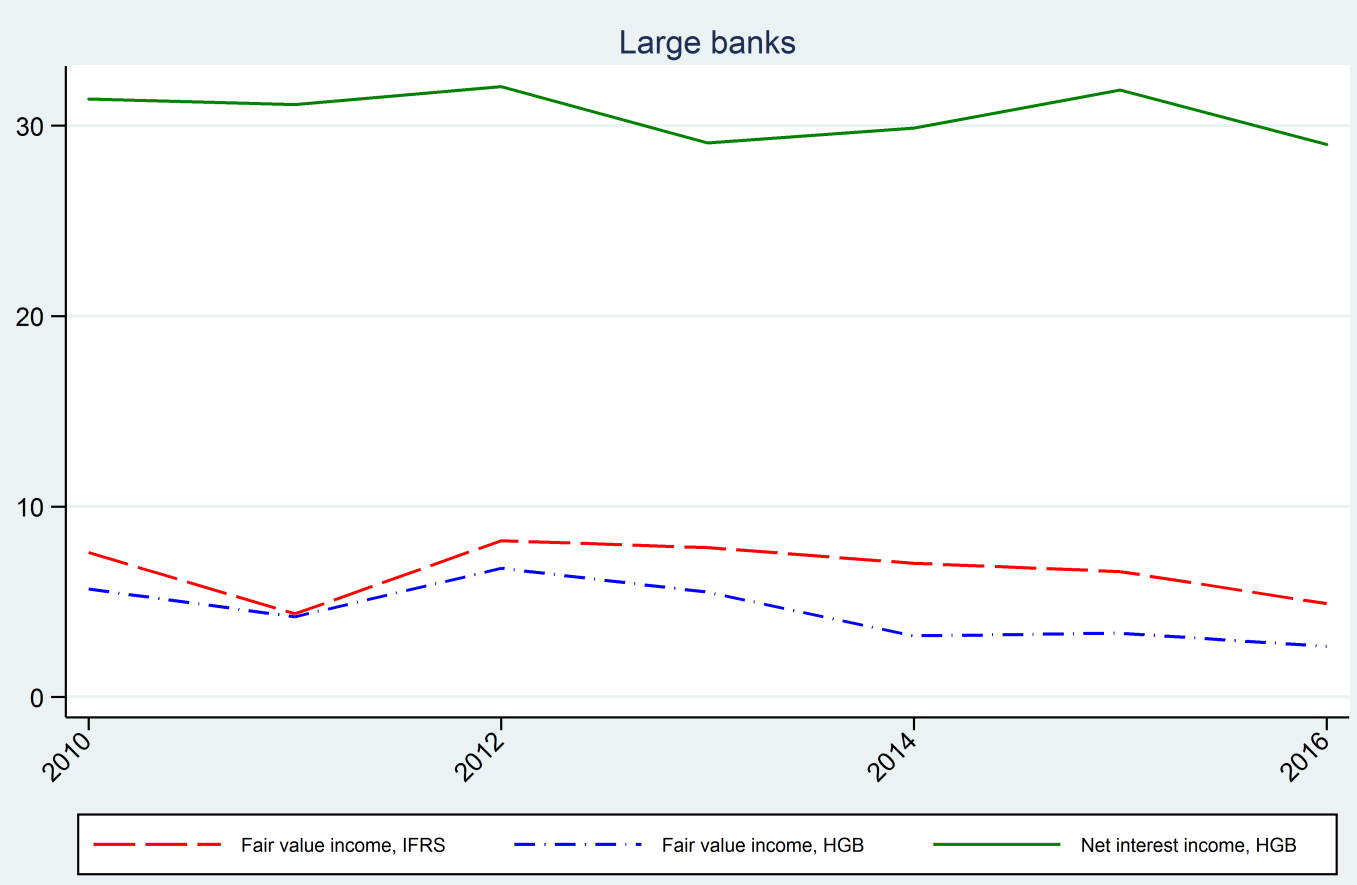

Source: Bundesbank. Own calculations. In billion EUR. IFRS trading income is only available as an aggregate statistic for all banks holdings under IFRS, which is roughly equivalent to the summed income over all Major banks, Landesbanken, and cooperative central banks.

Figure 17: Average Net Income

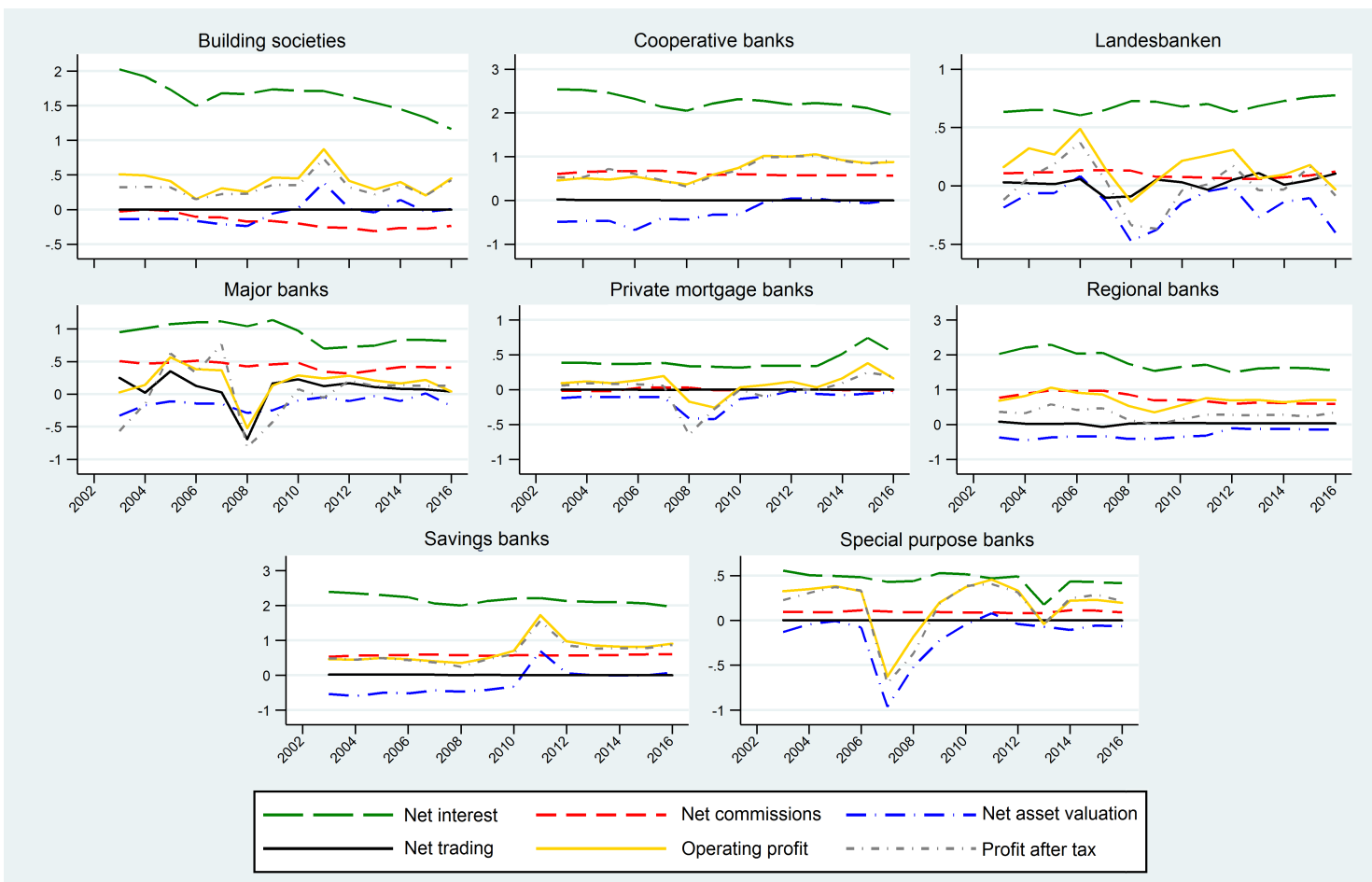

Source: Bundesbank P\&L Statistics. Own calculations. Net income components relative to total assets by bank group. The averages are calculated as weighted averages of total assets. 
Figure 18: Evolution of Return on Equity

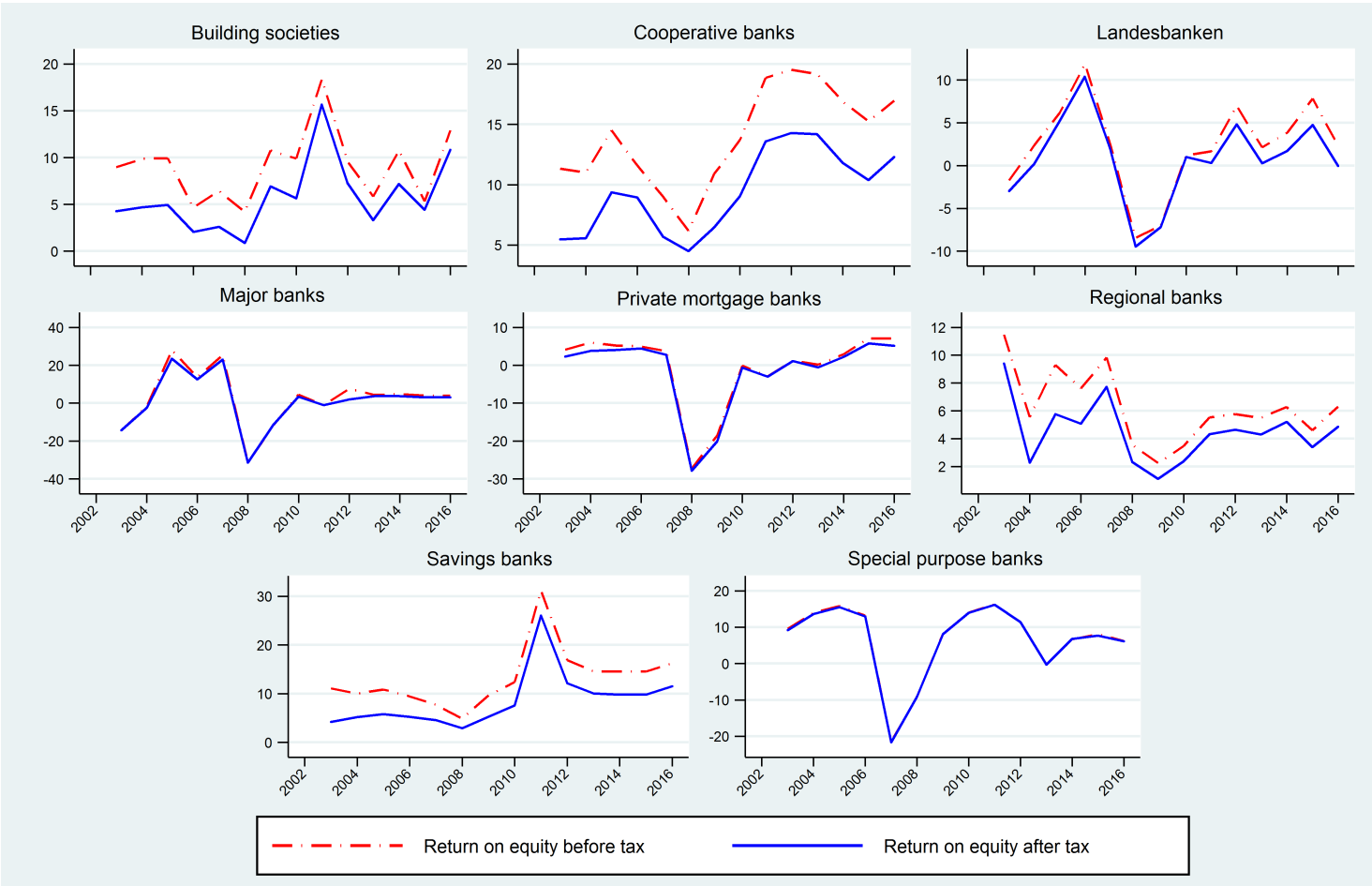

Source: Bundesbank P\&L Statistics. Own calculations. The averages are calculated as weighted averages of total assets.

Figure 19: Illustration of Impact of the Interaction Term on Net Interest Income

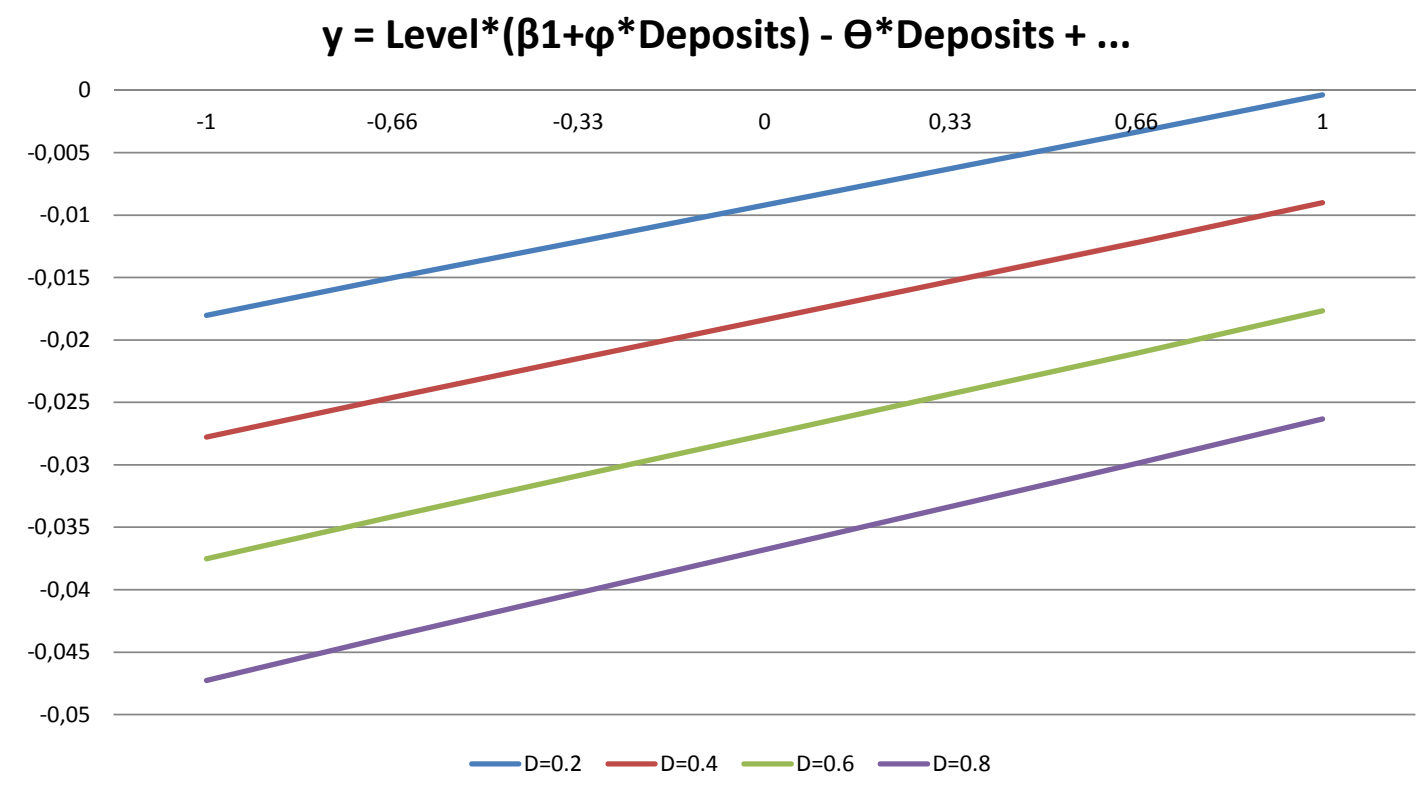

Source: Bundesbank. Own calculations based on the results of the System-GMM estimator for all banks. As the level of the interest rate increases, net interest income increases. However, higher levels of deposit shares imply a lower net interest income. This relationship becomes only significant when breaking through the ZLB. 

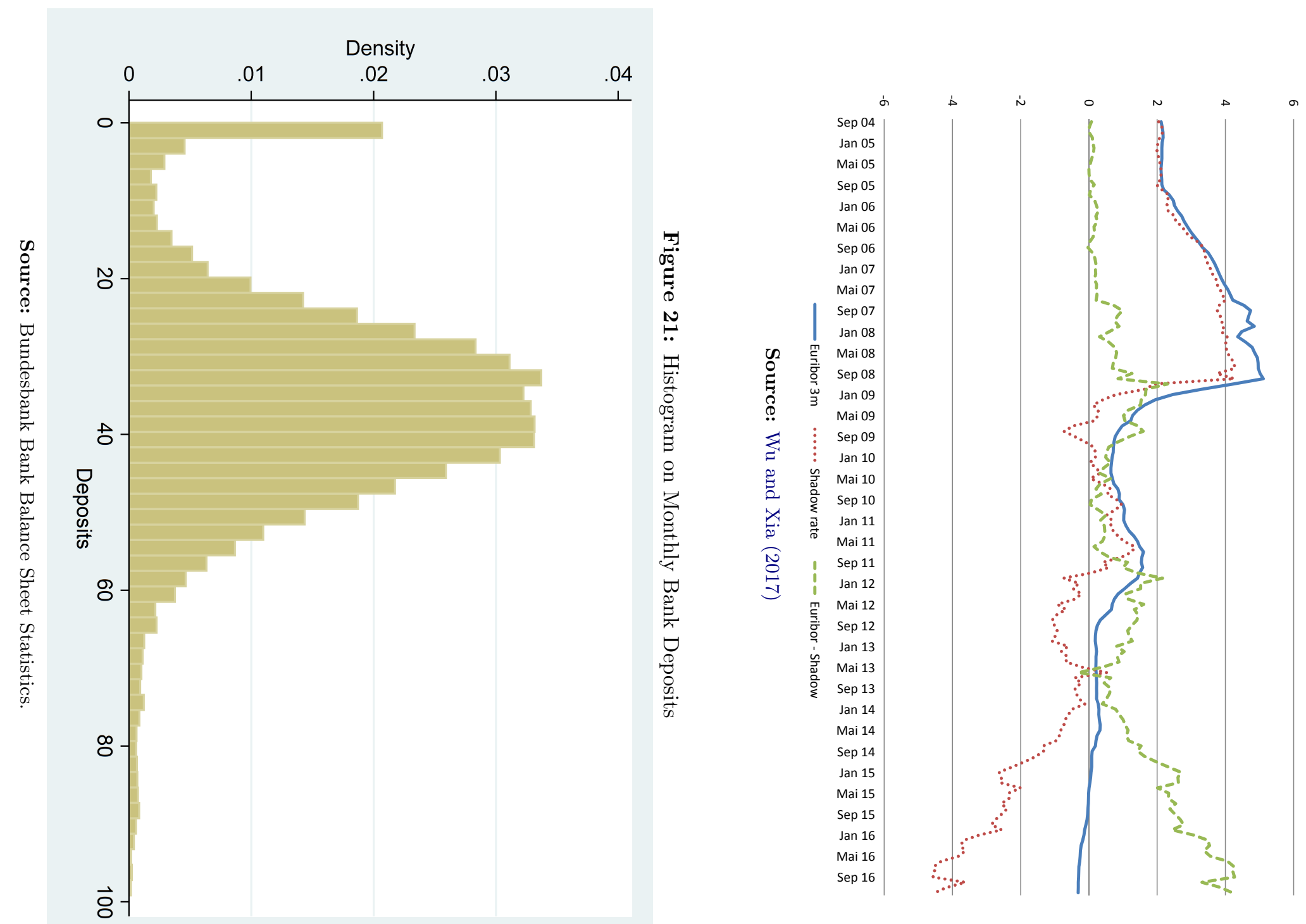

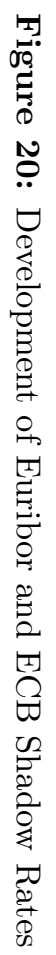


Table 3: Effect of Unconventional Monetary Policy on Net Interest Income

\section{(1)}

(2)

(3)

(4)

(5)

Fixed effects System-GMM Large banks Small banks Regional banks

\begin{tabular}{|c|c|c|c|c|c|}
\hline Net interest, lag & $\begin{array}{c}0.5072^{* * *} \\
(0.0338)\end{array}$ & $\begin{array}{c}0.5528^{* * *} \\
(0.0391)\end{array}$ & $\begin{array}{c}0.2103^{*} \\
(0.1064)\end{array}$ & $\begin{array}{c}0.5167^{* * *} \\
(0.0118)\end{array}$ & $\begin{array}{c}0.4775 * * * \\
(0.0280)\end{array}$ \\
\hline Level & $0.0315^{*}$ & 0.0074 & -0.1886 & 0.0056 & $0.2241^{* * *}$ \\
\hline & $(0.0177)$ & $(0.0202)$ & $(0.2524)$ & $(0.0093)$ & $(0.0424)$ \\
\hline Level, sq. & $-0.0080^{* *}$ & -0.0039 & 0.0327 & $-0.0069 * * *$ & $-0.0264^{* * *}$ \\
\hline & $(0.0035)$ & $(0.0028)$ & $(0.0345)$ & $(0.0014)$ & $(0.0069)$ \\
\hline Slope & $0.0751^{* * *}$ & $0.0519^{* * *}$ & 0.0083 & $0.0641^{* * *}$ & $0.0664^{* *}$ \\
\hline & $(0.0069)$ & $(0.0072)$ & $(0.1261)$ & $(0.0044)$ & $(0.0267)$ \\
\hline Deposit ratio $*$ level & 0.0004 & -0.0004 & -0.0037 & $0.0007^{* * *}$ & -0.0004 \\
\hline & $(0.0002)$ & $(0.0005)$ & $(0.0055)$ & $(0.0002)$ & $(0.0004)$ \\
\hline Deposit ratio $*$ UMP $*$ level & $0.0023^{* * *}$ & $0.0029^{* * *}$ & & $0.0028 * * *$ & $0.0029^{* *}$ \\
\hline & $(0.0004)$ & $(0.0004)$ & & $(0.0003)$ & $(0.0014)$ \\
\hline GDP growth YoY, lag & $-0.0026^{* * *}$ & -0.0014 & 0.0094 & $-0.0022^{* * *}$ & 0.0007 \\
\hline & $(0.0009)$ & $(0.0010)$ & $(0.0325)$ & $(0.0006)$ & $(0.0036)$ \\
\hline House price index, lag & $-0.0023^{* *}$ & -0.0013 & 0.0000 & -0.0007 & $0.0206^{* * *}$ \\
\hline & $(0.0010)$ & $(0.0013)$ & $(0.0438)$ & $(0.0007)$ & $(0.0039)$ \\
\hline Bank size, lag & $-0.1477 * * *$ & $-0.1617^{* * *}$ & 0.2360 & $-0.0562 * * *$ & $-0.1021^{* * *}$ \\
\hline & $(0.0211)$ & $(0.0390)$ & $(0.1786)$ & $(0.0127)$ & $(0.0319)$ \\
\hline Leverage ratio, lag & -0.0018 & $-0.0225^{* * *}$ & -0.0072 & $-0.0326^{* * *}$ & $-0.0205^{* * *}$ \\
\hline & $(0.0044)$ & $(0.0066)$ & $(0.0415)$ & $(0.0056)$ & $(0.0039)$ \\
\hline Efficiency, lag & -0.0236 & $0.1874^{* * *}$ & -0.5110 & $0.1950 * * *$ & 0.0522 \\
\hline & $(0.0395)$ & $(0.0352)$ & $(0.4624)$ & $(0.0221)$ & $(0.1397)$ \\
\hline Loan ratio, lag & $0.0019^{* * *}$ & $-0.0065^{* * *}$ & 0.0013 & $-0.0037 * * *$ & $-0.0041^{* *}$ \\
\hline & $(0.0006)$ & $(0.0014)$ & $(0.0038)$ & $(0.0006)$ & $(0.0017)$ \\
\hline Deposit ratio, lag & -0.0007 & $-0.0048^{* * *}$ & $0.0375^{*}$ & $-0.0042^{* * *}$ & -0.0001 \\
\hline & $(0.0006)$ & $(0.0013)$ & $(0.0190)$ & $(0.0006)$ & $(0.0017)$ \\
\hline Observations & 20,485 & 20,485 & 84 & 17,954 & 1,737 \\
\hline Number of banks & 1,599 & 1,599 & 14 & 1,383 & 155 \\
\hline$R^{2}$ & 0.4838 & & 0.2240 & & \\
\hline Autocorrelation 1 & & -4.581 & & -17.15 & -2.729 \\
\hline Autocorrelation 2 & & 0.0715 & & 0.374 & 0.175 \\
\hline
\end{tabular}

Notes: The fixed effects estimator uses clustered bank standard errors. The System-GMM estimator is specified as a two-step estimator with robust standard errors. The maximum number of lags used as instruments for the System-GMM estimator is capped at three. The regressions on small and regional banks also use the System-GMM estimator. To avoid the structural break through the Balance Sheet Modernisation Act, the data set for large banks is reduced to start in 2010. Also, since this subset of the data set is a small $\mathrm{N}$, small $\mathrm{T}$ sample the fixed effects estimator is employed. $* * *=p<0.01, * *=p<0.05$, and $*=p<0.1$. 
Table 4: Effect of Unconventional Monetary Policy on Net Commissions

\section{(1)}

(2)

(3)

(4)

(5)

Fixed effects System-GMM Large banks Small banks Regional banks

\begin{tabular}{|c|c|c|c|c|c|}
\hline Net commission, lag & $\begin{array}{c}0.6284^{* * *} \\
(0.0431)\end{array}$ & $\begin{array}{c}0.8798^{* * *} \\
(0.1255)\end{array}$ & $\begin{array}{c}0.4509 * * * \\
(0.1435)\end{array}$ & $\begin{array}{c}0.8189 * * * \\
(0.0133)\end{array}$ & $\begin{array}{c}0.8164^{* * *} \\
(0.0229)\end{array}$ \\
\hline \multirow{2}{*}{ Level } & 0.0013 & 0.0094 & -0.0054 & 0.0016 & 0.0611 \\
\hline & $(0.0106)$ & $(0.0091)$ & $(0.0597)$ & $(0.0031)$ & $(0.0380)$ \\
\hline \multirow[t]{2}{*}{ Level, sq. } & -0.0010 & 0.0021 & -0.0022 & -0.0001 & -0.0076 \\
\hline & $(0.0018)$ & $(0.0013)$ & $(0.0076)$ & $(0.0004)$ & $(0.0070)$ \\
\hline \multirow[t]{2}{*}{ Slope } & $-0.0281^{* * *}$ & $-0.0126^{* * *}$ & -0.0433 & $-0.0176^{* * *}$ & -0.0269 \\
\hline & $(0.0062)$ & $(0.0031)$ & $(0.0287)$ & $(0.0016)$ & $(0.0213)$ \\
\hline \multirow[t]{2}{*}{ Deposit ratio $*$ level } & -0.0000 & $-0.0007^{* *}$ & $-0.0012^{* *}$ & $0.0001^{* *}$ & $-0.0008^{*}$ \\
\hline & $(0.0003)$ & $(0.0003)$ & $(0.0005)$ & $(0.0001)$ & $(0.0004)$ \\
\hline \multirow[t]{2}{*}{ Deposit ratio $*$ UMP $*$ level } & $0.0012^{* * *}$ & $0.0014^{* * *}$ & & $0.0009 * * *$ & $0.0025^{* *}$ \\
\hline & $(0.0003)$ & $(0.0004)$ & & $(0.0001)$ & $(0.0011)$ \\
\hline \multirow[t]{2}{*}{ GDP growth YoY, lag } & $-0.0028 * * *$ & $0.0008^{* *}$ & -0.0003 & $-0.0017^{* * *}$ & $-0.0048^{*}$ \\
\hline & $(0.0008)$ & $(0.0004)$ & $(0.0060)$ & $(0.0002)$ & $(0.0026)$ \\
\hline \multirow[t]{2}{*}{ House price index, lag } & $0.0036^{* * *}$ & $0.0043^{* * *}$ & 0.0145 & $0.0052^{* * *}$ & $0.0109 * * *$ \\
\hline & $(0.0007)$ & $(0.0010)$ & $(0.0089)$ & $(0.0003)$ & $(0.0036)$ \\
\hline \multirow[t]{2}{*}{ DAX, lag } & $-0.0818^{* * *}$ & $-0.1484^{* * *}$ & & $-0.0922^{* * *}$ & $-0.2263^{* * *}$ \\
\hline & $(0.0167)$ & $(0.0175)$ & & $(0.0042)$ & $(0.0577)$ \\
\hline \multirow[t]{2}{*}{ Bank size, lag } & $-0.1535 * * *$ & 0.0438 & 0.0867 & $0.0274^{* * *}$ & 0.0148 \\
\hline & $(0.0469)$ & $(0.0865)$ & $(0.0780)$ & $(0.0054)$ & $(0.0284)$ \\
\hline \multirow[t]{2}{*}{ Leverage ratio, lag } & 0.0041 & 0.0021 & -0.0100 & $-0.0107^{* * *}$ & 0.0041 \\
\hline & $(0.0048)$ & $(0.0130)$ & $(0.0072)$ & $(0.0027)$ & $(0.0050)$ \\
\hline \multirow[t]{2}{*}{ Efficiency, lag } & 0.0470 & $0.0585^{* *}$ & 0.1136 & $0.0331 * * *$ & $0.3996^{* * *}$ \\
\hline & $(0.0320)$ & $(0.0293)$ & $(0.0777)$ & $(0.0072)$ & $(0.1498)$ \\
\hline \multirow[t]{2}{*}{ Loan ratio, lag } & -0.0007 & $-0.0049 * * *$ & 0.0015 & $-0.0029 * * *$ & $-0.0053^{* * *}$ \\
\hline & $(0.0006)$ & $(0.0016)$ & $(0.0018)$ & $(0.0002)$ & $(0.0016)$ \\
\hline \multirow[t]{2}{*}{ Deposit ratio, lag } & 0.0007 & 0.0011 & $0.0105^{*}$ & $-0.0005^{* *}$ & 0.0003 \\
\hline & $(0.0008)$ & $(0.0012)$ & $(0.0049)$ & $(0.0002)$ & $(0.0017)$ \\
\hline Observations & 20,485 & 20,485 & 84 & 17,954 & 1,737 \\
\hline Number of banks & 1,599 & 1,599 & 14 & 1,383 & 155 \\
\hline$R^{2}$ & 0.4764 & & 0.3770 & & \\
\hline Autocorrelation 1 & & -3.863 & & -18.32 & -4.158 \\
\hline Autocorrelation 2 & & -2.391 & & 0.254 & -2.327 \\
\hline
\end{tabular}

Notes: The fixed effects estimator uses clustered bank standard errors. The System-GMM estimator is specified as a two-step estimator with robust standard errors. The maximum number of lags used as instruments for the System-GMM estimator is capped at three. The regressions on small and regional banks also use the System-GMM estimator. To avoid the structural break through the Balance Sheet Modernisation Act, the data set for large banks is reduced to start in 2010. Also, since this subset of the data set is a small $\mathrm{N}$, small $\mathrm{T}$ sample the fixed effects estimator is employed. $* * *=p<0.01, * *=p<0.05$, and $*=p<0.1$. 
Table 5: Effect of Unconventional Monetary Policy on Net Provisions

\section{(1)}

(2)

(3)

(4)

(5)

Fixed effects System-GMM Large banks Small banks Regional banks

\begin{tabular}{|c|c|c|c|c|c|}
\hline Net provision, lag & $\begin{array}{c}0.0416^{* * *} \\
(0.0128)\end{array}$ & $\begin{array}{c}0.4764^{* * *} \\
(0.0353)\end{array}$ & $\begin{array}{l}0.0082 \\
(0.1588)\end{array}$ & $\begin{array}{c}0.4607^{* * *} \\
(0.0237)\end{array}$ & $\begin{array}{c}0.3685^{* * *} \\
(0.0231)\end{array}$ \\
\hline Level & $-0.3850^{* * *}$ & $-0.3290 * * *$ & 0.3534 & $-0.3847^{* * *}$ & $-0.1028^{* *}$ \\
\hline & $(0.0240)$ & $(0.0386)$ & $(0.3131)$ & $(0.0261)$ & $(0.0422)$ \\
\hline Level, sq. & $0.0510^{* * *}$ & $0.0534^{* * *}$ & -0.0747 & $0.0654^{* * *}$ & 0.0091 \\
\hline & $(0.0043)$ & $(0.0063)$ & $(0.0448)$ & $(0.0041)$ & $(0.0079)$ \\
\hline Slope & 0.0133 & $0.0300^{*}$ & -0.0835 & $0.0708^{* * *}$ & $-0.0565^{* *}$ \\
\hline & $(0.0101)$ & $(0.0172)$ & $(0.1621)$ & $(0.0119)$ & $(0.0242)$ \\
\hline Deposit ratio $*$ level & -0.0002 & $0.0008^{*}$ & 0.0014 & $0.0011^{* *}$ & -0.0003 \\
\hline & $(0.0002)$ & $(0.0005)$ & $(0.0070)$ & $(0.0005)$ & $(0.0002)$ \\
\hline Deposit ratio $*$ UMP $*$ level & $0.0019^{* * *}$ & $0.0061^{* * *}$ & & $0.0074^{* * *}$ & -0.0001 \\
\hline & $(0.0006)$ & $(0.0011)$ & & $(0.0008)$ & $(0.0012)$ \\
\hline GDP growth YoY, lag & $0.0544^{* * *}$ & $0.0498^{* * *}$ & 0.0183 & $0.0596^{* * *}$ & 0.0065 \\
\hline & $(0.0016)$ & $(0.0027)$ & $(0.0481)$ & $(0.0018)$ & $(0.0040)$ \\
\hline House price index, lag & $-0.0207^{* * *}$ & 0.0015 & 0.0346 & $-0.0052^{* *}$ & -0.0042 \\
\hline & $(0.0014)$ & $(0.0028)$ & $(0.0454)$ & $(0.0021)$ & $(0.0033)$ \\
\hline DAX, lag & $-0.1064^{* * *}$ & $-0.3738 * * *$ & & $-0.3666^{* * *}$ & -0.0960 \\
\hline & $(0.0259)$ & $(0.0392)$ & & $(0.0296)$ & $(0.0611)$ \\
\hline Bank size, lag & 0.0155 & $0.0535^{*}$ & -0.2817 & $-0.1272^{* * *}$ & $0.0467^{*}$ \\
\hline & $(0.0319)$ & $(0.0302)$ & $(0.2916)$ & $(0.0313)$ & $(0.0276)$ \\
\hline Leverage ratio, lag & 0.0067 & 0.0199 & $0.0866^{*}$ & $-0.1345^{* * *}$ & 0.0023 \\
\hline & $(0.0049)$ & $(0.0139)$ & $(0.0410)$ & $(0.0178)$ & $(0.0032)$ \\
\hline Efficiency, lag & -0.0541 & $3.4639 * * *$ & -0.1873 & $3.6311^{* * *}$ & $1.1478 * * *$ \\
\hline & $(0.0766)$ & $(0.2343)$ & $(0.3995)$ & $(0.1522)$ & $(0.1690)$ \\
\hline Loan ratio, lag & $-0.0061^{* * *}$ & $-0.0106^{* * *}$ & -0.0024 & $-0.0106^{* * *}$ & -0.0010 \\
\hline & $(0.0008)$ & $(0.0027)$ & $(0.0065)$ & $(0.0017)$ & $(0.0011)$ \\
\hline Deposit ratio, lag & $0.0067 * * *$ & $0.0207^{* * *}$ & -0.0093 & $0.0372^{* * *}$ & -0.0014 \\
\hline & $(0.0010)$ & $(0.0041)$ & $(0.0272)$ & $(0.0022)$ & $(0.0012)$ \\
\hline Observations & 20,485 & 20,485 & 84 & 17,954 & 1,737 \\
\hline Number of banks & 1,599 & 1,599 & 14 & 1,383 & 155 \\
\hline$R^{2}$ & 0.2631 & & 0.2717 & & \\
\hline Autocorrelation 1 & & -21.16 & & -25.21 & -5.820 \\
\hline Autocorrelation 2 & & -2.496 & & -4.678 & 0.401 \\
\hline
\end{tabular}

Notes: The fixed effects estimator uses clustered bank standard errors. The System-GMM estimator is specified as a two-step estimator with robust standard errors. The maximum number of lags used as instruments for the System-GMM estimator is capped at three. The regressions on small and regional banks also use the System-GMM estimator. To avoid the structural break through the Balance Sheet Modernisation Act, the data set for large banks is reduced to start in 2010. Also, since this subset of the data set is a small $\mathrm{N}$, small $\mathrm{T}$ sample the fixed effects estimator is employed. $* * *=p<0.01, * *=p<0.05$, and $*=p<0.1$. 
Table 6: Effect of Unconventional Monetary Policy on Net Trading Income

$$
\text { (1) }
$$

(3)

(4)

(5)

Fixed effects System-GMM Large banks Small banks Regional banks

Net trading, lag

Level

Level, sq.

Slope

Trading book assets * DAX

Trading book liabilities * DAX

GDP growth YoY, lag

DAX, lag

Bank size, lag

Leverage ratio, lag

Efficiency, lag

Loan ratio, lag

Deposit ratio, lag

Trading book assets, lag

Trading book liabilities, lag

\begin{tabular}{|c|c|c|c|c|}
\hline-0.0784 & 0.0953 & 0.0070 & 0.0228 & $0.1562^{*}$ \\
\hline$(0.0605)$ & $(0.0972)$ & $(0.1148)$ & (0.0390) & $(0.0946)$ \\
\hline-0.0008 & -0.0002 & -0.0893 & $-0.0009 * * *$ & 0.0037 \\
\hline$(0.0013)$ & (0.0009) & $(0.0932)$ & $(0.0003)$ & $(0.0055)$ \\
\hline$-0.0022^{* * *}$ & $-0.0017^{* * *}$ & -0.0401 & -0.0004 & -0.0034 \\
\hline$(0.0007)$ & $(0.0006)$ & $(0.0449)$ & $(0.0002)$ & $(0.0026)$ \\
\hline $0.0082^{* * *}$ & $0.0065^{* * *}$ & 0.1464 & $0.0026 * * *$ & 0.0094 \\
\hline$(0.0024)$ & $(0.0016)$ & $(0.2345)$ & $(0.0007)$ & $(0.0092)$ \\
\hline-0.0001 & 0.0000 & -0.0003 & -0.0010 & 0.0000 \\
\hline$(0.0000)$ & $(0.0001)$ & $(0.0004)$ & $(0.0007)$ & $(0.0001)$ \\
\hline 0.0000 & -0.0000 & -0.0001 & 0.0008 & -0.0000 \\
\hline$(0.0001)$ & $(0.0001)$ & $(0.0003)$ & $(0.0006)$ & $(0.0001)$ \\
\hline $0.0015 * * *$ & $0.0012^{* * *}$ & 0.0406 & $0.0005^{* * *}$ & 0.0018 \\
\hline$(0.0004)$ & $(0.0003)$ & $(0.0401)$ & $(0.0001)$ & $(0.0019)$ \\
\hline $0.0104^{* *}$ & $0.0068^{* *}$ & 0.0699 & $0.0026^{* *}$ & 0.0207 \\
\hline$(0.0045)$ & $(0.0033)$ & $(0.3717)$ & $(0.0011)$ & $(0.0166)$ \\
\hline-0.0015 & 0.0081 & 0.0699 & 0.0019 & -0.0028 \\
\hline$(0.0017)$ & $(0.0112)$ & $(0.1996)$ & $(0.0016)$ & $(0.0077)$ \\
\hline-0.0003 & 0.0005 & 0.0251 & 0.0002 & -0.0002 \\
\hline$(0.0002)$ & $(0.0008)$ & $(0.0257)$ & $(0.0002)$ & $(0.0006)$ \\
\hline $0.0030^{*}$ & 0.0007 & -0.0271 & -0.0000 & 0.0137 \\
\hline$(0.0018)$ & $(0.0010)$ & $(0.1689)$ & $(0.0005)$ & $(0.0288)$ \\
\hline-0.0000 & 0.0001 & -0.0010 & -0.0000 & -0.0003 \\
\hline$(0.0001)$ & $(0.0001)$ & $(0.0028)$ & $(0.0000)$ & $(0.0005)$ \\
\hline 0.0001 & 0.0001 & 0.0051 & 0.0000 & -0.0000 \\
\hline$(0.0001)$ & $(0.0001)$ & $(0.0055)$ & $(0.0000)$ & $(0.0002)$ \\
\hline-0.0007 & 0.0024 & -0.0052 & 0.0131 & 0.0023 \\
\hline$(0.0012)$ & $(0.0016)$ & $(0.0053)$ & $(0.0091)$ & $(0.0016)$ \\
\hline 0.0014 & -0.0015 & 0.0101 & -0.0102 & -0.0022 \\
\hline$(0.0012)$ & $(0.0018)$ & $(0.0064)$ & $(0.0074)$ & $(0.0015)$ \\
\hline 9,520 & 9,520 & 79 & 8,279 & 868 \\
\hline 1,596 & 1,596 & 14 & 1,382 & 150 \\
\hline \multirow[t]{3}{*}{0.0202} & & 0.3530 & & \\
\hline & -2.893 & & -3.203 & -2.076 \\
\hline & -0.728 & & -0.256 & -0.393 \\
\hline
\end{tabular}

Notes: The fixed effects estimator uses clustered bank standard errors. The System-GMM estimator is specified as a two step estimator with robust standard errors. The maximum number of lags used as instruments for the System-GMM estimator is capped at three. The regressions on small and regional banks also use the System-GMM estimator. As fair value accounting for the trading portfolio starts only in 2010 , the data set is reduced accordingly for all estimators. Also, since this subset of the data set is a small $\mathrm{N}$, small $\mathrm{T}$ sample the fixed effects estimator is employed. $* * *=p<0.01, * *=p<0.05$, and $*=p<0.1$. 
Table 7: Effect of UMP on Net Interest Income Using Shadow Rates

(1)

(2)

(3)

(4)

$(5)$

Fixed effects System-GMM Large banks Small banks Regional banks

\begin{tabular}{|c|c|c|c|c|c|}
\hline Net interest, lag & $\begin{array}{c}0.5041^{* * *} \\
(0.0344)\end{array}$ & $\begin{array}{c}0.5227 * * * \\
(0.0434)\end{array}$ & $\begin{array}{c}0.2178^{* *} \\
(0.0859)\end{array}$ & $\begin{array}{c}0.4885^{* * *} \\
(0.0124)\end{array}$ & $\begin{array}{c}0.4863^{* * *} \\
(0.0274)\end{array}$ \\
\hline Level & $0.0341^{*}$ & 0.0063 & -0.5233 & $0.0316^{* * *}$ & $0.2074 * * *$ \\
\hline & $(0.0180)$ & $(0.0151)$ & $(0.4002)$ & $(0.0078)$ & $(0.0403)$ \\
\hline Level, sq. & $-0.0070^{* *}$ & $-0.0055^{*}$ & 0.0748 & $-0.0089 * * *$ & $-0.0262^{* * *}$ \\
\hline & $(0.0034)$ & $(0.0029)$ & $(0.0534)$ & $(0.0014)$ & $(0.0068)$ \\
\hline Slope & $0.0738 * * *$ & $0.0481 * * *$ & -0.0959 & $0.0631^{* * *}$ & $0.0552^{* *}$ \\
\hline & $(0.0069)$ & $(0.0074)$ & $(0.1574)$ & $(0.0044)$ & $(0.0275)$ \\
\hline Deposits $*$ (level - shadow) & $-0.0005^{* * *}$ & $-0.0006^{* * *}$ & -0.0109 & $-0.0005^{* * *}$ & $-0.0009^{* * *}$ \\
\hline & $(0.0001)$ & $(0.0001)$ & $(0.0086)$ & $(0.0001)$ & $(0.0003)$ \\
\hline GDP growth YoY, lag & $-0.0018^{* *}$ & -0.0014 & -0.0061 & $-0.0022^{* * *}$ & 0.0013 \\
\hline & $(0.0009)$ & $(0.0009)$ & $(0.0352)$ & $(0.0006)$ & $(0.0037)$ \\
\hline House price index, lag & -0.0012 & 0.0012 & 0.0267 & -0.0003 & $0.0229 * * *$ \\
\hline & $(0.0012)$ & $(0.0013)$ & $(0.0497)$ & $(0.0007)$ & $(0.0039)$ \\
\hline Bank size, lag & $-0.1473^{* * *}$ & $-0.1901^{* * *}$ & -0.0321 & $-0.0505^{* * *}$ & $-0.0934^{* * *}$ \\
\hline & $(0.0212)$ & $(0.0445)$ & $(0.3088)$ & $(0.0126)$ & $(0.0300)$ \\
\hline Leverage ratio, lag & -0.0012 & $-0.0235^{* * *}$ & 0.0124 & $-0.0252^{* * *}$ & $-0.0222^{* * *}$ \\
\hline & $(0.0043)$ & $(0.0065)$ & $(0.0508)$ & $(0.0054)$ & $(0.0037)$ \\
\hline Efficiency, lag & -0.0125 & $0.1898 * * *$ & -0.3753 & $0.1742^{* * *}$ & 0.1036 \\
\hline & $(0.0367)$ & $(0.0334)$ & $(0.4084)$ & $(0.0218)$ & $(0.1419)$ \\
\hline Loan ratio, lag & $0.0019 * * *$ & $-0.0056^{* * *}$ & -0.0022 & $-0.0032^{* * *}$ & $-0.0041^{* *}$ \\
\hline & $(0.0006)$ & $(0.0013)$ & $(0.0038)$ & $(0.0006)$ & $(0.0016)$ \\
\hline Deposit ratio, lag & 0.0003 & $-0.0036^{* * *}$ & 0.0318 & $-0.0027^{* * *}$ & 0.0009 \\
\hline & $(0.0007)$ & $(0.0011)$ & $(0.0239)$ & $(0.0006)$ & $(0.0016)$ \\
\hline Observations & 20,485 & 20,485 & 84 & 17,954 & 1,737 \\
\hline Number of banks & 1,599 & 1,599 & 14 & 1,383 & 155 \\
\hline$R^{2}$ & 0.4838 & & 0.2393 & & \\
\hline Autocorrelation 1 & & -4.485 & & -17.06 & -2.740 \\
\hline Autocorrelation 2 & & -0.103 & & -0.331 & 0.194 \\
\hline
\end{tabular}

Notes: The fixed effects estimator uses clustered bank standard errors. The System-GMM estimator is specified as a two step estimator with robust standard errors. The maximum number of lags used as instruments for the System-GMM estimator is capped at three. The regressions on small and regional banks also use the System-GMM estimator. To avoid the structural break through the Balance Sheet Modernisation Act, the data set for large banks is reduced to start in 2010 . Also, since this subset of the data set is a small $\mathrm{N}$, small $\mathrm{T}$ sample the fixed effects estimator is employed. $* * *=p<0.01, * *=p<0.05$, and $*=p<0.1$. 
Table 8: Effect of UMP on Net Commissions Using Shadow Rates

$$
\text { (1) }
$$

(4)

(5)

Fixed effects System-GMM Large banks Small banks Regional banks

\begin{tabular}{|c|c|c|c|c|c|}
\hline Net commission, lag & $\begin{array}{c}0.6293^{* * *} \\
(0.0432)\end{array}$ & $\begin{array}{c}0.8979 * * * \\
(0.1086)\end{array}$ & $\begin{array}{c}0.4099 * * \\
(0.1462)\end{array}$ & $\begin{array}{c}0.8095^{* * *} \\
(0.0122)\end{array}$ & $\begin{array}{c}0.8281^{* * *} \\
(0.0199)\end{array}$ \\
\hline \multirow[t]{2}{*}{ Level } & 0.0113 & -0.0005 & -0.0952 & $0.0106^{* * *}$ & 0.0490 \\
\hline & $(0.0104)$ & $(0.0070)$ & $(0.0644)$ & $(0.0026)$ & $(0.0392)$ \\
\hline \multirow[t]{2}{*}{ Level, sq. } & -0.0026 & 0.0005 & 0.0090 & $-0.0011^{* *}$ & -0.0098 \\
\hline & $(0.0018)$ & $(0.0013)$ & $(0.0086)$ & $(0.0004)$ & $(0.0079)$ \\
\hline \multirow[t]{2}{*}{ Slope } & $-0.0254^{* * *}$ & $-0.0162^{* * *}$ & $-0.0709^{* *}$ & $-0.0160 * * *$ & -0.0296 \\
\hline & $(0.0062)$ & $(0.0030)$ & $(0.0242)$ & $(0.0016)$ & $(0.0219)$ \\
\hline \multirow[t]{2}{*}{ Deposits $*$ (level - shadow) } & $-0.0003^{* * *}$ & $-0.0004^{* * *}$ & -0.0028 & $-0.0002^{* * *}$ & $-0.0011^{* * *}$ \\
\hline & $(0.0001)$ & $(0.0001)$ & $(0.0024)$ & $(0.0000)$ & $(0.0003)$ \\
\hline \multirow[t]{2}{*}{ GDP growth YoY, lag } & $-0.0031^{* * *}$ & 0.0004 & -0.0045 & $-0.0018^{* * *}$ & -0.0042 \\
\hline & $(0.0008)$ & $(0.0004)$ & $(0.0044)$ & $(0.0002)$ & $(0.0026)$ \\
\hline \multirow[t]{2}{*}{ House price index, lag } & $0.0051 * * *$ & $0.0060 * * *$ & $0.0216^{* *}$ & $0.0055^{* * *}$ & $0.0154^{* * *}$ \\
\hline & $(0.0011)$ & $(0.0010)$ & $(0.0082)$ & $(0.0003)$ & $(0.0040)$ \\
\hline \multirow[t]{2}{*}{ DAX, lag } & $-0.0602^{* * *}$ & $-0.1251^{* * *}$ & & $-0.0772 * * *$ & $-0.1832^{* * *}$ \\
\hline & $(0.0184)$ & $(0.0128)$ & & $(0.0043)$ & $(0.0551)$ \\
\hline \multirow[t]{2}{*}{ Bank size, lag } & $-0.1550 * * *$ & 0.0539 & 0.0239 & $0.0209^{* * *}$ & 0.0076 \\
\hline & $(0.0467)$ & $(0.0764)$ & $(0.0773)$ & $(0.0052)$ & $(0.0296)$ \\
\hline \multirow[t]{2}{*}{ Leverage ratio, lag } & 0.0037 & 0.0051 & -0.0042 & $-0.0103^{* * *}$ & 0.0015 \\
\hline & $(0.0048)$ & $(0.0148)$ & $(0.0073)$ & $(0.0027)$ & $(0.0056)$ \\
\hline \multirow[t]{2}{*}{ Efficiency, lag } & 0.0498 & $0.0568^{* *}$ & $0.1458^{*}$ & $0.0319^{* * *}$ & $0.4976^{* * *}$ \\
\hline & $(0.0325)$ & $(0.0252)$ & $(0.0760)$ & $(0.0072)$ & $(0.1478)$ \\
\hline \multirow[t]{2}{*}{ Loan ratio, lag } & -0.0006 & $-0.0038^{* * *}$ & 0.0007 & $-0.0026^{* * *}$ & $-0.0062^{* * *}$ \\
\hline & $(0.0006)$ & $(0.0014)$ & $(0.0017)$ & $(0.0002)$ & $(0.0017)$ \\
\hline \multirow[t]{2}{*}{ Deposit ratio, lag } & 0.0012 & 0.0005 & 0.0086 & -0.0001 & 0.0017 \\
\hline & $(0.0008)$ & $(0.0012)$ & $(0.0049)$ & $(0.0002)$ & $(0.0016)$ \\
\hline Observations & 20,485 & 20,485 & 84 & 17,954 & 1,737 \\
\hline Number of banks & 1,599 & 1,599 & 14 & 1,383 & 155 \\
\hline$R^{2}$ & 0.4768 & & 0.3876 & & \\
\hline Autocorrelation 1 & & -4.085 & & -18.31 & -4.226 \\
\hline Autocorrelation 2 & & -2.397 & & -0.0528 & -2.330 \\
\hline
\end{tabular}

Notes: The fixed effects estimator uses clustered bank standard errors. The System-GMM estimator is specified as a two step estimator with robust standard errors. The maximum number of lags used as instruments for the System-GMM estimator is capped at three. The regressions on small and regional banks also use the System-GMM estimator. To avoid the structural break through the Balance Sheet Modernisation Act, the data set for large banks is reduced to start in 2010. Also, since this subset of the data set is a small $\mathrm{N}$, small $\mathrm{T}$ sample the fixed effects estimator is employed. $* * *=p<0.01, * *=p<0.05$, and $*=p<0.1$. 
Table 9: Effect of UMP on Net Provisions Using Shadow Rates

(1)

(1) (2)

$(2)$

(3)

(4)

(5)

System-GMM Large banks Small banks Regional banks

\begin{tabular}{lccccc} 
Net provisions, lag & $0.0451^{* * *}$ & $0.5012^{* * *}$ & 0.0095 & $0.4966^{* * *}$ & $0.3646^{* * *}$ \\
& $(0.0128)$ & $(0.0354)$ & $(0.2088)$ & $(0.0240)$ & $(0.0227)$ \\
Level & $-0.3528^{* * *}$ & $-0.2718^{* * *}$ & 0.6316 & $-0.3055^{* * *}$ & $-0.1163^{* * *}$ \\
& $(0.0241)$ & $(0.0361)$ & $(0.4799)$ & $(0.0242)$ & $(0.0430)$ \\
Level, sq. & $0.0456^{* * *}$ & $0.0464^{* * *}$ & -0.1113 & $0.0550^{* * *}$ & 0.0101 \\
& $(0.0043)$ & $(0.0060)$ & $(0.0689)$ & $(0.0041)$ & $(0.0080)$ \\
Slope & $0.0218^{* *}$ & $0.0425^{* *}$ & 0.0006 & $0.0794^{* * *}$ & $-0.0548^{* *}$ \\
& $(0.0102)$ & $(0.0167)$ & $(0.1776)$ & $(0.0117)$ & $(0.0245)$ \\
Deposits * (level - shadow) & $-0.0010^{* * *}$ & $-0.0024^{* * *}$ & 0.0092 & $-0.0031^{* * *}$ & -0.0002 \\
& $(0.0001)$ & $(0.0002)$ & $(0.0104)$ & $(0.0002)$ & $(0.0003)$ \\
GDP growth YoY, lag & $0.0536^{* * *}$ & $0.0503^{* * *}$ & 0.0306 & $0.0583^{* * *}$ & $0.0071^{*}$ \\
& $(0.0016)$ & $(0.0026)$ & $(0.0572)$ & $(0.0018)$ & $(0.0040)$ \\
House price index, lag & $-0.0151^{* * *}$ & $0.0104^{* * *}$ & 0.0114 & $0.0087^{* * *}$ & -0.0032 \\
& $(0.0016)$ & $(0.0030)$ & $(0.0448)$ & $(0.0024)$ & $(0.0032)$ \\
DAX, lag & -0.0413 & $-0.2258^{* * *}$ & & $-0.1392^{* * *}$ & -0.0848 \\
& $(0.0278)$ & $(0.0412)$ & & $(0.0309)$ & $(0.0593)$ \\
Bank size, lag & 0.0091 & 0.0216 & -0.0788 & $-0.1664^{* * *}$ & 0.0402 \\
& $(0.0329)$ & $(0.0290)$ & $(0.4272)$ & $(0.0304)$ & $(0.0266)$ \\
Leverage ratio, lag & 0.0052 & 0.0124 & $0.0777^{*}$ & $-0.1488^{* * *}$ & 0.0020 \\
& $(0.0049)$ & $(0.0149)$ & $(0.0413)$ & $(0.0179)$ & $(0.0031)$ \\
Efficiency, lag & -0.0164 & $3.6913^{* * *}$ & -0.2554 & $3.8968^{* * *}$ & $1.1340 * * *$ \\
& $(0.0774)$ & $(0.2376)$ & $(0.2209)$ & $(0.1541)$ & $(0.1694)$ \\
Loan ratio, lag & $-0.0059^{* * *}$ & $-0.0089^{* * *}$ & -0.0001 & $-0.0075^{* * *}$ & -0.0010 \\
& $(0.0009)$ & $(0.0027)$ & $(0.0083)$ & $(0.0017)$ & $(0.0011)$ \\
Deposit ratio, lag & $0.0083^{* * *}$ & $0.0256^{* * *}$ & -0.0098 & $0.0392^{* * *}$ & -0.0014 \\
& $(0.0010)$ & $(0.0041)$ & $(0.0259)$ & $(0.0021)$ & $(0.0012)$ \\
& & & & & \\
\hline Observations & 20,485 & 20,485 & 84 & 17,954 & 1,737 \\
Number of banks & 1,599 & 1,599 & 14 & 1,383 & 155 \\
$R^{2}$ & 0.2647 & & 0.2810 & & -5.816 \\
Autocorrelation 1 & & -21.53 & & -25.40 & 0.396 \\
Autocorrelation 2 & -2.664 & & -4.530 &
\end{tabular}

Notes: The fixed effects estimator uses clustered bank standard errors. The System-GMM estimator is specified as a two step estimator with robust standard errors. The maximum number of lags used as instruments for the System-GMM estimator is capped at three. The regressions on small and regional banks also use the System-GMM estimator. To avoid the structural break through the Balance Sheet Modernisation Act, the data set for large banks is reduced to start in 2010. Also, since this subset of the data set is a small $\mathrm{N}$, small $\mathrm{T}$ sample the fixed effects estimator is employed. $* * *=p<0.01, * *=p<0.05$, and $*=p<0.1$. 
Table 10: Effect of Unconventional Monetary Policy on Bank Leverage Using Shadow Rates

\section{(1)}

(2)

(3)

(4)

(5)

Fixed effects System-GMM Large banks Small banks Regional banks

Leverage ratio, lag

$\begin{array}{ccc}0.9485 * * * & 0.8110^{* * *} & 0.9354^{* * *} \\ (0.0057) & (0.0261) & (0.0265) \\ 0.0047 & 0.0534^{* * *} & -0.0499 \\ (0.0065) & (0.0193) & (0.0366) \\ -0.0014^{*} & -0.0071^{* * *} & 0.0040 \\ (0.0008) & (0.0026) & (0.0050) \\ -0.0021 & 0.0130^{*} & -0.0155 \\ (0.0021) & (0.0072) & (0.0306) \\ -0.0003^{* * *} & -0.0006 * * * & 0.0055 \\ (0.0001) & (0.0001) & (0.0038) \\ 0.0003 & 0.0028 & 0.0098 \\ (0.0008) & (0.0023) & (0.0085) \\ 0.0033^{* * *} & 0.0082^{* * *} & -0.0008 \\ (0.0005) & (0.0023) & (0.0092) \\ -0.0582^{* *} & 0.4673^{* * *} & 0.0418 \\ (0.0242) & (0.1065) & (0.0648) \\ -0.0011^{* * *} & 0.0062^{* * *} & -0.0002 \\ (0.0003) & (0.0016) & (0.0004) \\ 0.0009 & -0.0076 & 0.0114 \\ (0.0006) & (0.0048) & (0.0085)\end{array}$

$0.9703^{* * *}$

$0.9408^{* * *}$

Level

(1)

Level, sq.

(and

Slope

Deposits * (level - shadow)

GDP growth YoY, lag

House price index, lag

Bank size, lag

Loan growth, lag

Deposit ratio, lag

\begin{tabular}{lccccc}
\hline Observations & 233,787 & 233,787 & 896 & 205,062 & 19,637 \\
Number of banks & 1,622 & 1,622 & 15 & 1,403 & 160 \\
$R^{2}$ & 0.9181 & & 0.8822 & 0.9463 & 0.9112 \\
Autocorrelation 1 & & -5.949 & & & \\
Autocorrelation 2 & 2.205 & & & \\
\hline
\end{tabular}

\begin{tabular}{lccccc}
\hline Observations & 233,787 & 233,787 & 896 & 205,062 & 19,637 \\
Number of banks & 1,622 & 1,622 & 15 & 1,403 & 160 \\
$R^{2}$ & 0.9181 & & 0.8822 & 0.9463 & 0.9112 \\
Autocorrelation 1 & & -5.949 & & & \\
Autocorrelation 2 & 2.205 & & & \\
\hline
\end{tabular}

1,622

$-5.949$

Autocorrelation 1

2.205

Notes: The fixed effects estimator uses clustered bank standard errors. The System-GMM estimator is specified as a two-step estimator with robust standard errors. The maximum number of lags used as instruments for the System-GMM estimator is capped at three. Since this regression is based on monthly balance sheet data, the $\mathrm{T}$ dimension is increased strongly decreasing the Nickell Bias. Hence, a fixed effects estimator is used for bank group specific regressions. To avoid the structural break through the Balance Sheet Modernisation Act, the data set for large banks is reduced to start in $2010 . * * *=p<0.01, * *=p<0.05$, and $*=p<0.1$. 
Table 11: Effect of Unconventional Monetary Policy on Loan Growth Using Shadow Rates

\begin{tabular}{|c|c|c|c|c|c|}
\hline & Fixed effects & $\begin{array}{c}(2) \\
\text { System-GMM }\end{array}$ & $\begin{array}{l}\text { (3) } \\
\text { Large banks }\end{array}$ & $\begin{array}{c}(4) \\
\text { Small banks }\end{array}$ & $\begin{array}{c}(5) \\
\text { Regional banks }\end{array}$ \\
\hline Loan growth, lag & $\begin{array}{c}0.7971 * * * \\
(0.0111)\end{array}$ & $\begin{array}{c}0.5780 * * * \\
(0.0289)\end{array}$ & $\begin{array}{c}0.8556^{* * *} \\
(0.0219)\end{array}$ & $\begin{array}{c}0.8758^{* * *} \\
(0.0054)\end{array}$ & $\begin{array}{c}0.7318^{* * *} \\
(0.0181)\end{array}$ \\
\hline Level & $\begin{array}{c}-0.0085 \\
(0.0503)\end{array}$ & $\begin{array}{c}-0.4620^{* *} \\
(0.2276)\end{array}$ & $\begin{array}{r}-1.4451 \\
(1.0391)\end{array}$ & $\begin{array}{c}-0.0609^{* *} \\
(0.0270)\end{array}$ & $\begin{array}{c}-0.1284 \\
(0.4125)\end{array}$ \\
\hline Level, sq. & $\begin{array}{c}-0.0219 * * * \\
(0.0072)\end{array}$ & $\begin{array}{l}-0.0169 \\
(0.0328)\end{array}$ & $\begin{array}{l}0.1722 \\
(0.1320)\end{array}$ & $\begin{array}{c}-0.0126 * * * \\
(0.0041)\end{array}$ & $\begin{array}{l}0.0421 \\
(0.0708)\end{array}$ \\
\hline Slope & $\begin{array}{c}-0.0864^{* * *} \\
(0.0246)\end{array}$ & $\begin{array}{r}-0.1149 \\
(0.0729)\end{array}$ & $\begin{array}{r}-0.7662 \\
(0.7466)\end{array}$ & $\begin{array}{c}-0.0766^{* * *} \\
(0.0141)\end{array}$ & $\begin{array}{l}0.2979 \\
(0.2222)\end{array}$ \\
\hline Deposits * (level - shadow) & $\begin{array}{c}-0.0038 * * * \\
(0.0006)\end{array}$ & $\begin{array}{c}-0.0079 * * * \\
(0.0024)\end{array}$ & $\begin{array}{r}-0.0117 \\
(0.0637)\end{array}$ & $\begin{array}{c}-0.0023^{* * *} \\
(0.0003)\end{array}$ & $\begin{array}{l}0.0010 \\
(0.0026)\end{array}$ \\
\hline GDP growth YoY, lag & $\begin{array}{c}0.0854^{* * *} \\
(0.0111)\end{array}$ & $\begin{array}{c}0.1334^{* * *} \\
(0.0295)\end{array}$ & $\begin{array}{l}0.1075 \\
(0.1428)\end{array}$ & $\begin{array}{c}0.0763^{* * *} \\
(0.0069)\end{array}$ & $\begin{array}{r}-0.0766 \\
(0.0988)\end{array}$ \\
\hline House price index, lag & $\begin{array}{l}0.0012 \\
(0.0048)\end{array}$ & $\begin{array}{c}-0.0400^{*} \\
(0.0241)\end{array}$ & $\begin{array}{r}-0.0500 \\
(0.2002)\end{array}$ & $\begin{array}{c}-0.0077^{* * *} \\
(0.0025)\end{array}$ & $\begin{array}{l}-0.0064 \\
(0.0361)\end{array}$ \\
\hline Bank size, lag & $\begin{array}{c}0.1384 \\
(0.1521)\end{array}$ & $\begin{array}{c}0.4087 \\
(0.7101)\end{array}$ & $\begin{array}{l}-0.5377 \\
(1.5462)\end{array}$ & $\begin{array}{c}0.3733^{* * *} \\
(0.0771)\end{array}$ & $\begin{array}{c}0.2403 \\
(0.2478)\end{array}$ \\
\hline Leverage ratio, lag & $\begin{array}{c}0.0141^{*} \\
(0.0083)\end{array}$ & $\begin{array}{c}0.5324^{* * *} \\
(0.1044)\end{array}$ & $\begin{array}{c}0.0081 \\
(0.0441)\end{array}$ & $\begin{array}{c}0.0337 * * * \\
(0.0047)\end{array}$ & $\begin{array}{c}0.0009 \\
(0.0223)\end{array}$ \\
\hline Deposit ratio, lag & $\begin{array}{c}0.0286 * * * \\
(0.0040)\end{array}$ & $\begin{array}{c}0.0848^{* * *} \\
(0.0269)\end{array}$ & $\begin{array}{l}0.1812 \\
(0.1507)\end{array}$ & $\begin{array}{c}0.0139 * * * \\
(0.0020)\end{array}$ & $\begin{array}{c}0.0393^{* * *} \\
(0.0103)\end{array}$ \\
\hline Observations & 234,154 & 234,154 & 960 & 205,210 & 19,703 \\
\hline Number of banks & 1,626 & 1,626 & 16 & 1,404 & 161 \\
\hline $\begin{array}{l}R^{2} \\
\text { Autocorrelation } 1 \\
\text { Autocorrelation } 2\end{array}$ & 0.6478 & $\begin{array}{c}-8.532 \\
1.676\end{array}$ & 0.7487 & 0.7821 & 0.5410 \\
\hline
\end{tabular}

Notes: The fixed effects estimator uses clustered bank standard errors. The System-GMM estimator is specified as a two-step estimator with robust standard errors. The maximum number of lags used as instruments for the System-GMM estimator is capped at three. Since this regression is based on monthly balance sheet data, the T dimension is increased strongly decreasing the Nickell Bias. Hence, a fixed effects estimator is used for bank group specific regressions. To avoid the structural break through the Balance Sheet Modernisation Act, the data set for large banks is reduced to start in $2010 . * * *=p<0.01, * *=p<0.05$, and $*=p<0.1$. 
Table 12: Diff-in-Diff on Net Interest Income

\begin{tabular}{lcccc}
\hline & $(1)$ & $(2)$ & $(3)$ & $(4)$ \\
& Net interest & Net interest & Net interest & Net interest \\
\hline & & & & \\
Dep. ratio * UMP & -0.0163 & $-0.0902^{* * *}$ & 0.0069 & $-0.0634^{* * *}$ \\
& $(0.0492)$ & $(0.0194)$ & $(0.0501)$ & $(0.0194)$ \\
& & & & \\
\hline Observations & 7,965 & 7,965 & 7,965 & 7,965 \\
Bank FE & $\mathrm{N}$ & $\mathrm{Y}$ & $\mathrm{N}$ & $\mathrm{Y}$ \\
Time FE & $\mathrm{N}$ & $\mathrm{N}$ & $\mathrm{Y}$ & $\mathrm{Y}$ \\
Number of banks & & 1,602 & & 1,602 \\
\hline
\end{tabular}

Notes: Treatment group is defined as banks with an above average deposit rate (Deposit ratio $=1$ if $>35 \%$ ). For yearly data, a time frame from 2012 to 2016 is chosen where UMP $=1$ for $t \geq 2014$. Clustered bank standard errors are used if bank FE are included. Otherwise standard errors are defined as robust. All dummies other than the interaction term are suppressed in output. $* * *=p<0.01, * *=p<0.05$, and $*=p<0.1$.

Table 13: Diff-in-Diff on Loan Growth

\begin{tabular}{lcccc}
\hline & $\begin{array}{c}(1) \\
\text { ln Loans }\end{array}$ & $\begin{array}{c}(2) \\
\ln \text { Loans }\end{array}$ & $\begin{array}{c}(3) \\
\ln \text { Loans }\end{array}$ & $\begin{array}{c}(4) \\
\ln \text { Loans }\end{array}$ \\
\hline & & & & \\
Dep. ratio * UMP & $-0.3182^{* *}$ & -0.1581 & $-0.4197^{* * *}$ & -0.2584 \\
& $(0.1235)$ & $(0.2920)$ & $(0.1243)$ & $(0.2962)$ \\
& & & & \\
\hline Observations & 57,394 & 57,394 & 57,394 & 57,394 \\
Bank FE & $\mathrm{N}$ & $\mathrm{Y}$ & $\mathrm{N}$ & $\mathrm{Y}$ \\
Time FE & $\mathrm{N}$ & $\mathrm{N}$ & $\mathrm{Y}$ & $\mathrm{Y}$ \\
Number of banks & & 1,600 & & 1,600 \\
\hline
\end{tabular}

Notes: Treatment group is defined as banks with an above average deposit rate (Deposit ratio $=1$ if $>35 \%$ ). For monthly data, a time frame from 2013 to 2015 is chosen where UMP $=1$ for $t>$ June 2014. Clustered bank standard errors are used if bank $\mathrm{FE}$ are included. Otherwise standard errors are defined as robust. All dummies other than the interaction term are suppressed in output. $* * *=p<0.01, * *=p<0.05$, and $*=p<0.1$ 